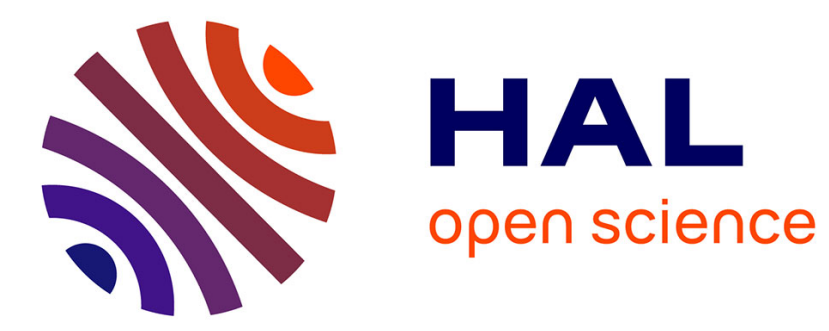

\title{
The Gangotri granite (Garhwal Himalaya): Laccolithic emplacement in an extending collisional belt
}

Bruno Scaillet, Arnaud Pêcher, Pierre Rochette, Michel Champenois

\section{To cite this version:}

Bruno Scaillet, Arnaud Pêcher, Pierre Rochette, Michel Champenois. The Gangotri granite (Garhwal Himalaya): Laccolithic emplacement in an extending collisional belt. Journal of Geophysical Research : Solid Earth, 1995, 100 (B1), pp.585-607. 10.1029/94JB01664 . insu-02484238

\section{HAL Id: insu-02484238 \\ https://hal-insu.archives-ouvertes.fr/insu-02484238}

Submitted on 19 Feb 2020

HAL is a multi-disciplinary open access archive for the deposit and dissemination of scientific research documents, whether they are published or not. The documents may come from teaching and research institutions in France or abroad, or from public or private research centers.
L'archive ouverte pluridisciplinaire HAL, est destinée au dépôt et à la diffusion de documents scientifiques de niveau recherche, publiés ou non, émanant des établissements d'enseignement et de recherche français ou étrangers, des laboratoires publics ou privés. 


\title{
The Gangotri granite (Garhwal Himalaya): Laccolithic emplacement in an extending collisional belt
}

\author{
Bruno Scaillet, ${ }^{1}$ Amaud Pêcher, ${ }^{2}$ Pierre Rochette, ${ }^{3}$ and Michel Champenois ${ }^{4}$
}

Abstract. The Gangotri Miocene leucogranite is composed of several laccoliths (6-7 km long, 1.5-2 km thick), which can be divided into two sets of lenses: the southern lenses, intruded in the lower part of the High Himalaya sedimentary cover, and the northem lenses, intruded in an older porphyritic biotite-bearing granite. In both cases, the magmatic fabric is commonly weak with no dominant stretching direction, although a rough $\mathrm{E}-\mathrm{W}$ trend is present in the northern lenses. The magnetic fabric is characterized by the fact that drastic changes in the direction, in the magnitude of the magnetic parameters, or in the fabric type (planar or linear) may take place over very short distances. Measurements of preferred orientations in thin sections indicate that the strain regime was largely dominated by a coaxial component for both sets of lenses, in agreement with the large dispersion observed in both the field and magnetic lineations. The comparison of the granite and host rock structures shows that the leucogranite emplacement dates the onset of the extensional tectonism in the High Himalaya range and is not related to a southward directed thrust event associated with the Main Central Thrust. This is exemplified by the vertical attitude of the feeder dikes that intrude the metasedimentary rocks beneath the southern lenses. The presence of these dikes indicates in turn that magma ascent occurred by fracture propagation. The spatial disposition of the southern lenses could have resulted either from the disruption of a single laccolithic intrusion by crustal scale boudinage due to a northern gravity backslide of the top of the Tibetan Slab or from the intrusion of independent laccoliths. The use of the elastic bending theory of Pollard and Johnson (1973) shows that in both hypotheses, the current laccolith sizes are compatible with a laccolithic mode of magma emplacement. However, neither the density contrast between the magma and its enclosing rocks nor the lithological boundary between the Tibetan Slab and the overlying Tibetan metasedimentary series controlled the level of magma emplacement. Rather, flat-lying collapse structures, which intersected the upward propagating magma dikes, are the most likely causes of magma arrest. Such a mechanism was favored by the schist-rich lithology of the metasedimentary host rocks. In addition, field relationships indicate that the melt supply through the dike system was a continuous, rather than pulsed, process.

Existing numerical treatments on the rates of magma transport through fractures show that in such a case, the laccoliths could have been built in less than 100 years. This short time of emplacement, the small size of the laccoliths, and their peripheral disposition relative to the Badrinath granite suggest that the Gangotri lenses may represent the initial stage of pluton accretion in the High Himalaya which ultimately gave rise to a much larger massif such as the Manaslu granite.

\section{Introduction}

This paper presents the results of a structural study of the Badrinath or Gangotri granite, one of the High Himalayan leucogranite (HHL) (Figure 1).These HHL are some of the rare magmatic products that postdate the collision between the Indian subcontinent and Eurasia, around $40 \mathrm{Ma}$ [Molnar, 1984; Le Fort, 1989]. Over the last few years, considerable

\footnotetext{
${ }^{1}$ Centre de Recherche sur la Synthèse et la Chimie des Minéraux, Centre National de la Recherche Scientifique, Orléans, France.

${ }^{2}$ Unité de Recherche Associée 69, Centre National de la Recherche Scientifique, Grenoble, France.

${ }^{3}$ Géochimie et Magnétisme des Roches, Faculté Saint Jérôme, Marseille, France.

${ }^{4}$ Centre de Recherche Pétrographique et Géochimique, Centre National de la Recherche Scientifique, Vandoeuvre-Lès-Nancy, France.
}

Copyright 1995 by the American Geophysical Union.

Paper number $94 \mathrm{JB} 01664$.

0148-0227/95/94JB-01664\$05.00 work has been devoted to the understanding of the geochemistry of these granites [e.g., Vidal et al., 1982; Blattner et al., 1983; Deniel et al., 1987; France-Lanord and Le Fort, 1988], but detailed structural studies remain scarce (e.g., Burg et al. [1984] on thin sills of leucogranite south of Nyalam, Tibet, and Pêcher et al. [1991] on the eastward extension of Manaslu granite, the Chhokang arm). Thus information about the mechanism of emplacement of these bodies or about the relationships between the structures of the plutons and their surroundings is severely lacking, yet such information is necessary to constrain emplacement models. In this paper, we discuss emplacement of the Badrinath-Gangotri granite (hereinafter called Gangotri granite) in relation to Himalayan tectonics, using several sets of data: field data, anisotropy of magnetic susceptibility (AMS) data, and shapepreferred orientation data. With these data we are able to develop a laccolithic model of magma emplacement and to discuss its implications on the Himalayan orogeny.

\section{Geological Setting}

The main lithotectonics units of this area are [Pêcher and Scaillet, 1989] from bottom to top (Figure 1): (1) the upper 

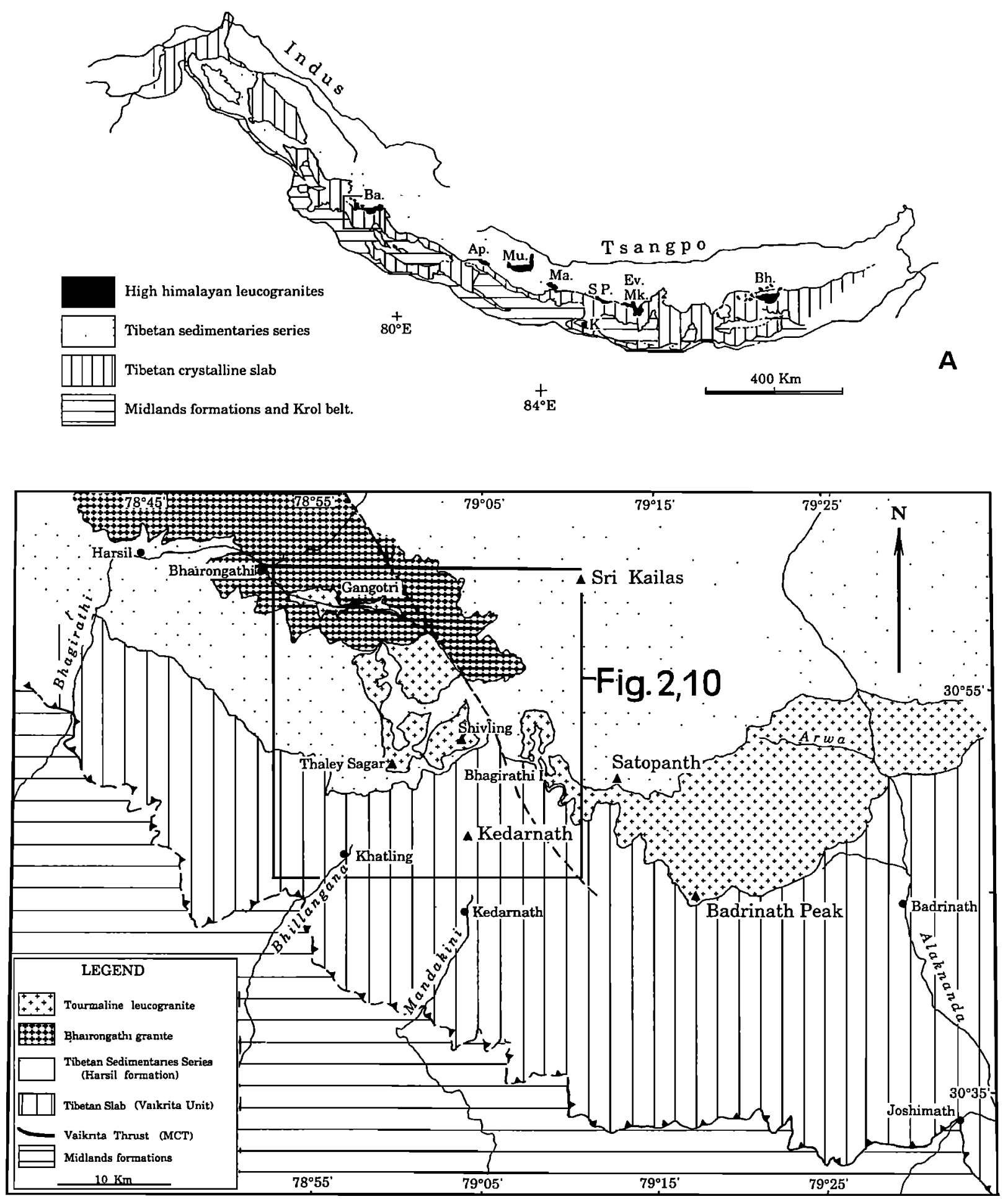

$\mathbf{B}$

Figure. 1. (a) Simplified geological map of the Himalaya range (modified after Le Fort [1986]). The main High Himalayan leucogranites are Badrinath (Ba), Api (Ap), Mustang (Mu), Manaslu, (Ma), Shisha Pangma (SP), Everest-Makalu (Ev-Mk), Bhutan (Bh). (b) Enlargement of Badrinath area (modified from Scaillet et al. [1990]) showing the location of Figures 2 and 10.

part of the Midlands Formations, dominated by thick levels of orthogneisses with a strong streching lineation, marking the Main Central Thrust (MCT) transport direction; (2) the Higher Himalayan Crystalline (HHC), or Tibetan Slab, separated from the underlying Midlands Formations by the Vaikrita
Thrust or MCT [Valdiya, 1979]. The HHC consists of a succession of biotite-garnet-kyanite gneisses, around $10 \mathrm{~km}$ thick, unmigmatized except at the very top where some orthogneissic levels display traces of partial melting; and (3) the lowest part of the Tibetan Sedimentary Series, the 
unfossiliferous pelitic Harsil formation [Pant, 1986]. At its base, under the granite lenses, it is composed of staurotidekyanite-garnet-biotite-muscovite assemblages, locally overprinted by cordierite+sillimanite, whereas higher up it contains staurotide-garnet-biotite, then biotite-muscovitechlorite assemblages. The Harsil formation is intruded by the Bhairongathi granite (BG), a biotite-rich porphyritic granite probably of Cambro-Ordovician age [Stern et al., 1989] and by the Gangotri leucogranite (Figure 1).

The Gangotri leucogranite was first recognized by Heim and Gansser [1939] and Auden [1949]. In the investigated area, it crops out as several lenses scattered over more than $400 \mathrm{~km}^{2}$ (Figure 1), each of which is several kilometers in length with a classic laccolithic shape. This granite is intrusive either in the BG (hereinafter referred to as the northern lenses) or in the Harsil formation (southern lenses) (Figure 2). Detailed petrographical and geochemical investigations of the leucogranite have been presented by Scaillet et al. [1990]. Each lens has a tourmaline-rich core, with biotite facies predominant along the borders. The grain size is fine to medium, rarely exceeding 2 or $3 \mathrm{~mm}$. In both facies, tourmaline and muscovite are clearly of magmatic origin. The zone of contact metamorphism developed around the granite is a few meters thick and is marked by annealing textures and crystallization of biotite, muscovite and tourmaline. Occurrences of andalusite have been also reported [Stern et al., 1989; Searle et al., 1993]. Isotopic K/Ar and $\mathrm{Rb} / \mathrm{Sr}$ data [Steitz et al., 1976; Stern et al., 1989] indicate

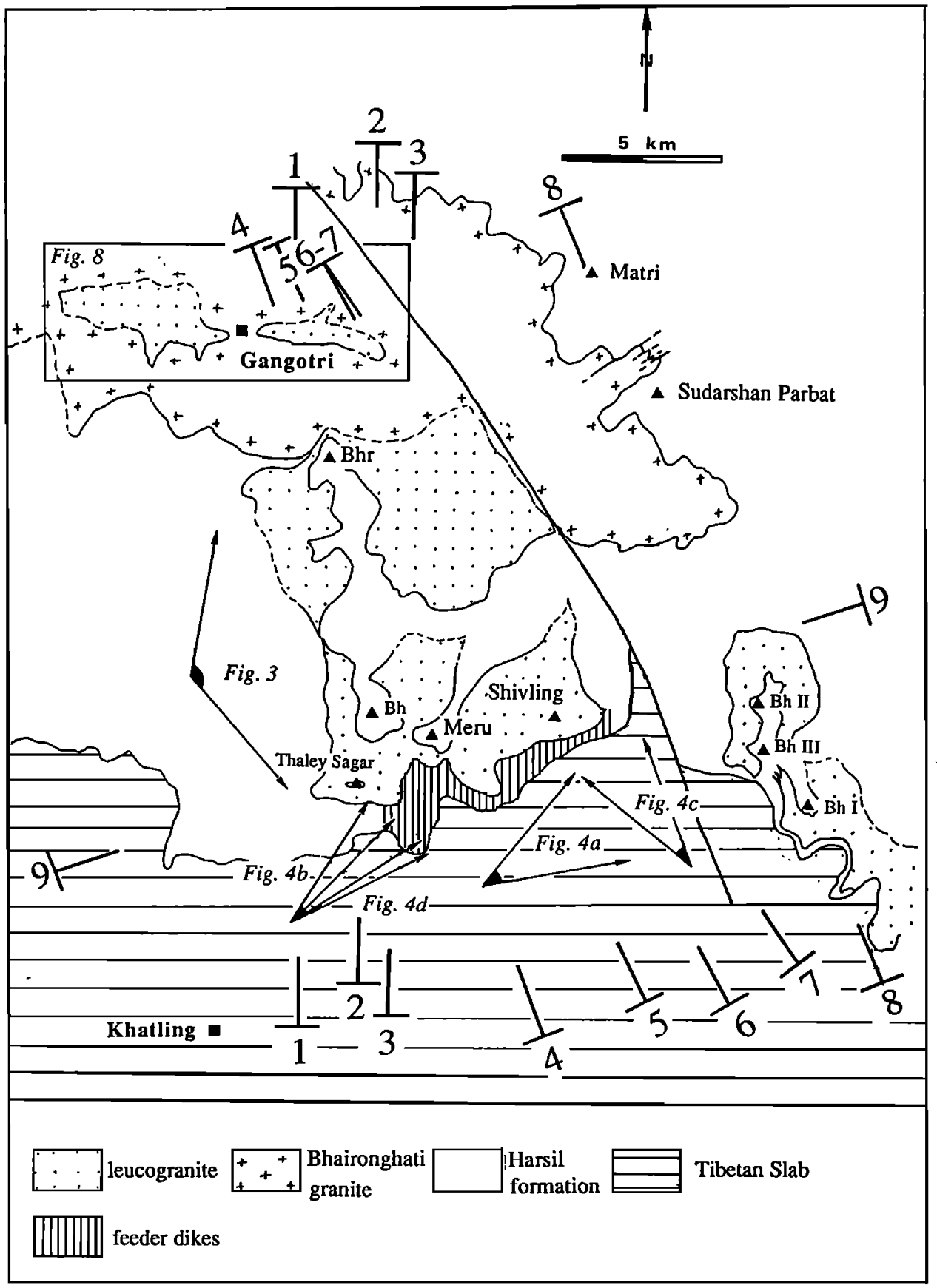

Figure 2. Cartographic distributicn of the leucogranitic lenses (dots) and of the main zone of feeder dikes (vertical pattern). The panoramic views (Figures 3 and 4) and the cross sections of the Figure 6 are located. 
Miocene ages (18.4 to $21.1 \mathrm{Ma}$ ), with significant heterogeneities in initial ${ }^{86} \mathrm{Sr} /{ }^{87} \mathrm{Sr}$ [Stern et al., 1989; Scaillet et al., 1990], similar to other HHL.

\section{Field Structure of the Granite}

\section{Three Dimensional Geometry of the Granite and Its Relations With Hosting Rocks}

The northern lenses lack exposures of their basal contact (Figure 2). Moreover, their top or lateral contacts are mappable only locally at an outcrop scale. Therefore the three-dimensional (3-D) shape of these lenses is not well constrained. By contrast, the southern lenses display an exceptionally well-defined 3-D laccolithic geometry (Figures 3 and 4 a) with a flat bottom and a convex, sometimes asymmetric, top. The length of each laccolith varies between 6 and $7 \mathrm{~km}$, while their maximum thickness ranges between 1.5 and $2 \mathrm{~km}$. The footwall contact of the laccolith is generally parallel to the host rock foliation although cross cutting angles of $20-30^{\circ}$ are common. At the top of the laccoliths, the contact is also roughly parallel to the surrounding foliation. However, in one case, a strong angular discordance has been observed (northern limb of the southern lens on Figure 3 ). This asymmetry suggests a northward sliding of the sediments overlying the granite. Below the laccoliths, the metamorphic foliation is usually flat and dips gently northward, sometimes affected by E-W striking north vergent folds, interpreted as northerly directed gravity collapse structures [Pêcher and Scaillet, 1989]. These folds are clearly crosscut by the leucogranite. At all locations and at any scale, the boundary between leucogranite and schist is an extremely sharp intrusive contact. Wherever the leucogranite lacks host rocks xenoliths, its contact is straight along hundreds of meters (Figure 3 ), without any lobation or geometrical irregularities. Close to either the basal or apical contacts, angular and elongated host rocks xenoliths with axial ratios ranging from 2 to 5 can be abundant (Figure 4). Large xenoliths may also be present in the central part of the lenses; however, xenoliths are never observed in the peripherical limbs (Figure 3 ). The internal fabric of the larger xenoliths is commonly parallel to the orientation of the surrounding metasedimentary rocks (Figure 4b), which suggests an injection mechanism with no rotational component.

At the scale of a few kilometers, the spatial disposition of the laccoliths reveals a large pinch and swsl type geometry. As an illustration, the overall geometry of the laccoliths has been reconstructed on a block diagram (Figure 5) and by a series of near radially disposed cross sections (Figure 6). These figures cover the area bounded at the south by the Thaley Sagar, Meru, and Shivling peaks, at the north by the southern contact of the BG granite and at the east by a late dextral fault (Figure 2). It is worth pointing out that given the large amount of exposure in this area (Figure 3), almost none of the leucogranite boundaries are inferred. Exceptions include the geometry of the relation between the Thaley Sagar and the Meru peak (cross section 9, Figure 6) and the southern termination of the southern lenses, which remains extrapolated. The most salient geometrical features of the leucogranite can be summarized as follows. First, there are two major laccoliths separated by an E-W zone (Figure 5 and cross sections 1 to 7, Figure 6). The distance between these two laccoliths increases progressively eastward (from $50 \mathrm{~m}$, cross section 2, to over $2000 \mathrm{~m}$, cross section 7). According to the present geological boundaries, the southern laccolith is affected by a north-south constriction, between the Meru and the Thaley Sagar peaks. If this geometry is correct, then the laccoliths of this area draw a "tablette de chocolat" pattern. Second, the asymmetry of the laccoliths increases to the east, in particular the more northerly (or thicker) increases eastward as well. Finally, the distance from the lower contacts of the lenses to the contact with the HHC-Harsil Formation increases, for either westerly or northerly directions. For example, on cross section 8 (through the Bhagirathi Peaks), this distance changes from nearly zero to more than $2000 \mathrm{~m}$ in only $6 \mathrm{~km}$. This is clear evidence that the level of emplacement is not governed by preexisting metamorphic structures or by the rheological differences existing between the $\mathrm{HHC}$ and the Harsil formation.

\section{Magmatic Fabric}

In thin section, a pre-full crystallization fabric [Hutton, 1988; Paterson et al., 1989], either isotropic or marked by a preferred orientation of the elongated minerals is typically observed, which indicates that the granite fabric is of magmatic origin. Traces of plastic deformation are rarely observed and are restricted to some border samples (GL88, GL89, GB132, GB137 and GB157, see Figure 10). In these cases, the preferred lattice orientation is never strong enough to allow the determination of the strain regime. The planar fabric is defined by alignment of mica and tourmaline. At the map scale, it shows a large dispersion with an average WNWESE orientation, dipping gently northward (Figure 7a). It is well developed at, or close to, the borders, where it is always parallel to the contacts and not with the foliation in the host metamorphic rock (Figure 8). A linear fabric is defined by the tourmaline, which is mainly in the laccolith cores. It is predominantly horizontal with no dominant direction (Figure $7 b$ ). However, at or close to the borders, it displays a constant orientation over a scale of a few meters, whereas in lens cores, angular variations of up to $90^{\circ}$ occur over short distances $(<10$ $m$ ). The data collected do not enable the construction of accurate finite strain trajectories in all the lenses except for those in the north (Figure 8). In the latter, the finite strain flattening defines a WNW-ESE elongated domal structure, except at the western and eastern terminations of the lenses, where the flattening plane is steeper and almost N-S. In summary, the overall leucogranite fabric is characterized mainly by (1) a low intensity of the postmagmatic strain, (2) large angular variations in the stretching direction, and (3) linear fabrics predominating over the planar fabrics in the cores of the lenses.

\section{Dike Organization}

The sections investigated contain three types of dikes: (1) a spectacular set of vertical granitic dikes, the feeder system of the laccoliths that are rooted in the HHC, crosscut the lowermost Harsil formation, and terminate in contact with the bottom of the granitic lenses (Figure 4), (2) a network of finegrained granite dikes in the western part of the area near Harsil (Figure 1), and (3) at the roof of the granitic lenses, a variably developed aplite-pegmatite complex. The first type has been observed only beneath the southern lenses, where they can be followed along a $1000-\mathrm{m}$ vertical cliff (Shivling-Thaley Sagar area, Figures 2 and 4c). Their typical geometry is illustrated by Figure 4: numerous dikes $10-20 \mathrm{~m}$ thick that intruded the 

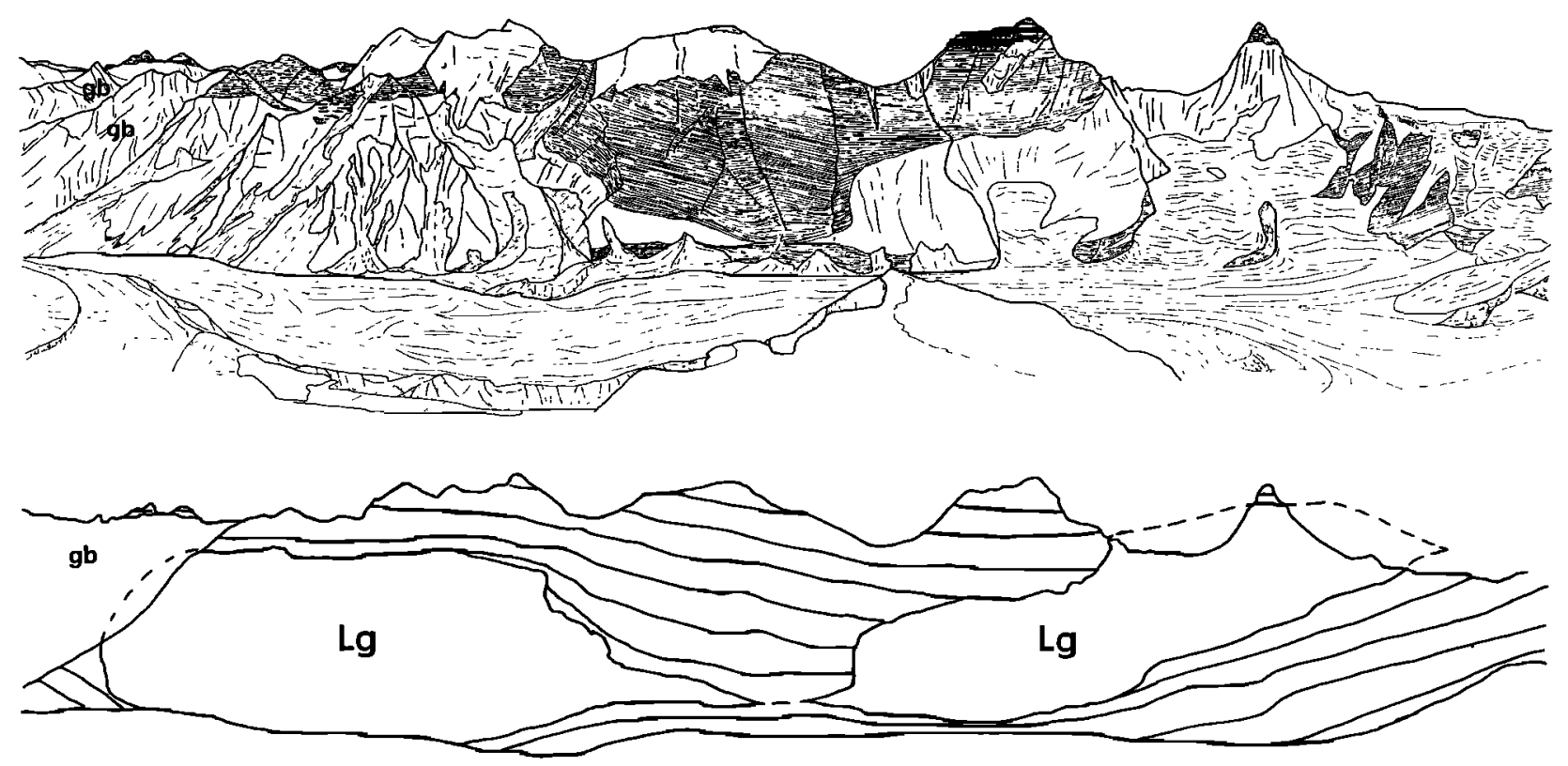

Flgure 3. (a) Panorama of two lenses cropping out along the right bank of the Kedar glacier, looking eastward from an altitude of $6100 \mathrm{~m}$. Open areas, two lenses of leucocranite. The southern lens is approximately $1000 \mathrm{~m}$ thick. Note in between the two lenses the truncation of the host rock foliation. North side of the view, the Bhairongathi granite (BG) is in the background, separated from the leucogranite by metasedimentary rocks. (b) Sketch of the same panorama outlining the geological contours. Lg, leucogranite.

metamorphic pile, which consists of two rheologically contrasting rock types, i.e., a massive competent level of orthogneisses (upper part of the HHC) and a less competent black schist level (Harsil formation). In the orthogneisses, the dikes are perpendicular to the lithological contacts, whereas in the black schists they are oblique to them (Figures $4 \mathrm{c}$ and d). This change in dike orientation is consistent with the sliding of the top of the pile (pelitic schist + leucogranite) toward the north or NW during and/or after the granite injection. The second type of dike has been observed in the north, near the village of Harsil, as abundant dikes of finegrained garnet-tourmaline granite, up to $40 \mathrm{~m}$ thick, oriented NNW and dipping ENE. They occur in a large-scale en echelon pattem, indicating a movement of the top of the pile toward the ENE. In thin section they show a magmatic fabric. The third type of dike is present in both the northem and southern lenses, but those in the north have been mainly studied. In the north, various aplites and pegmatite occur between the leucogranite and the surrounding BG granite as zones up to $100 \mathrm{~m}$ thick. The dikes strike approximately E-W (Figure 9) and dip either south or north at the southern and northem contacts respectively (Figure 9). This pattern may reflect a regional N-S extension, but it is probably also related to a cooling and shrinking effect of the leucogranite (volume loss upon crystallization can reach as much as $12 \%$ [Lange and Carmichael, 1987]) that was not completely balanced by the surrounding rigid old BG granite. At the top of the southern lenses, a similar but less extensive dike network also exists. Several dikes are isoclinally folded (with no clear asymmetry and fold axes parallel to the contact), indicating some flattening at the top of the granite, possibly due to a local ballooning effect. These dikes are crosscut by other undeformed dikes, analogous to those found above the northern lenses. The last important point concerning the third type of dikes is that they are seldom present within the leucogranite [Scaillet et al., 1990]

\section{Magnetic Study}

The consistency between field strain and kinematic measurements and the anisotropy of magnetic susceptibility (AMS) is now well established [e.g., Guillet et al., 1983; Bouchez et al., 1990; Gleizes et al., 1993; Bouillin et al., 1993]. In the surveyed area, no systematic AMS sampling was possible, due to sampling difficulties (field work was mainly carried out at altitudes of 4500 to $6000 \mathrm{~m}$ ), but samples (Figure 10) were preferentially collected from areas where the magmatic fabric is weak.

\section{Apparatus and Procedure}

The samples, oriented in the field, were cored in the laboratory with an amagnetic drill in order to obtain approximately four specimens (diameter of $2.5 \mathrm{~cm}$ and height of $2.2 \mathrm{~cm}$ ) per site (Table 1). The low field magnetic susceptibility of each specimen was then measured with a Kappabridge KLY-2 (sensivity is $5 \times 10^{-8} \mathrm{SI}$ ), along 15 directions following the procedure described by Jelinek [1979]. This allows the determination of the magnetic susceptibility tensor, described by the orientation and magnitude of its eigen vectors $K_{1}<K_{2}<K_{3}$. The $K_{i}$ values obtained have been corrected for the diamagnetic term (quartz and feldspar) using a value of $-14 \times 10^{-6} \mathrm{SI}$ [Bernier et al., 1987; Rochette, 1987]. From the corrected values, the anisotropy ratios $L=K_{1} / K_{2}, F=K_{2} / K_{3}$, and $P=K_{1} / K_{3}$ can be 
a

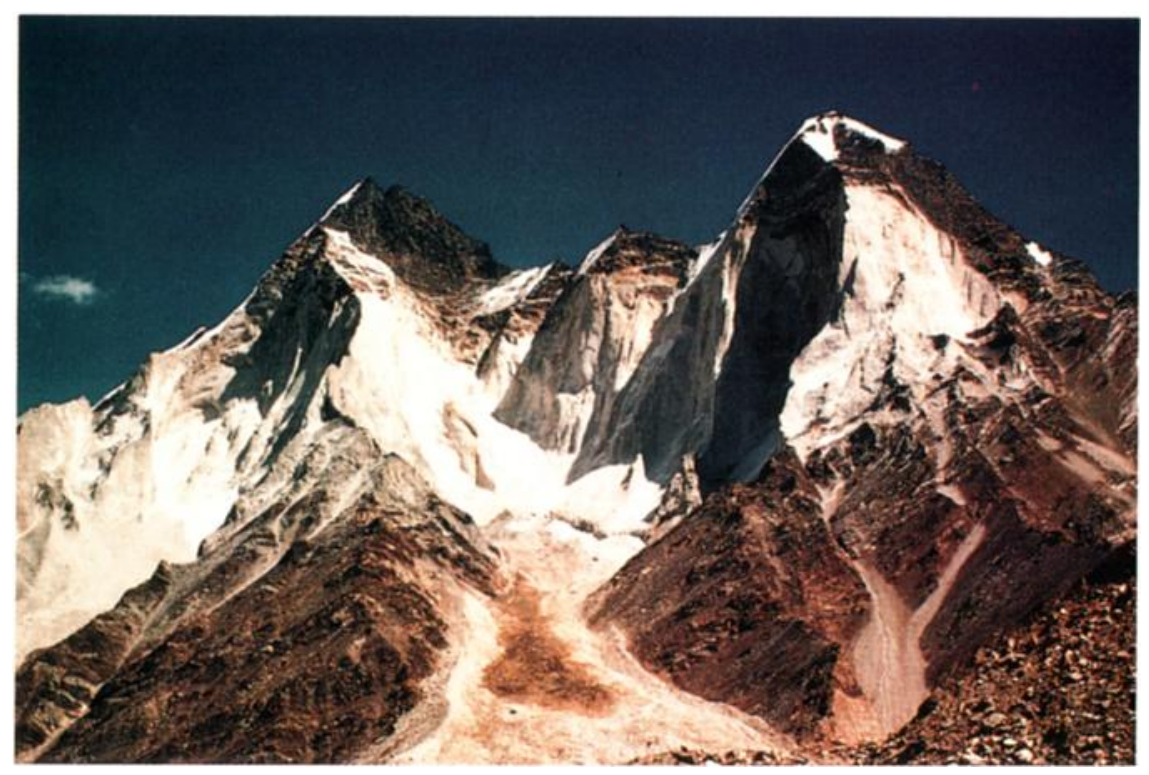

b

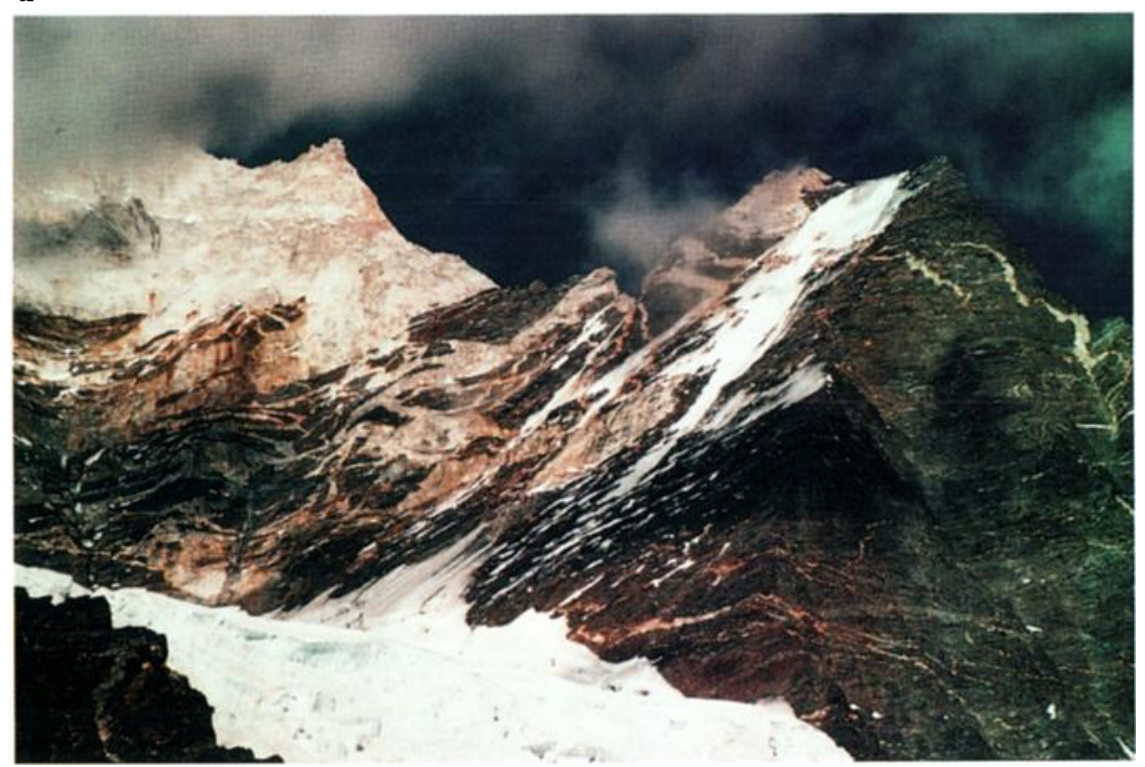

Figure 4. (a) Leucoranite lenses on the western bank of the Gangotri glacier. The thickness of the granitic lens, clearly visible in the East faces of Bhagirathi peaks II and III (the left and right summits respectively, altitudes of $6512 \mathrm{~m}$ and $6454 \mathrm{~m}$ ), is about $1000 \mathrm{~m}$. (b) Xenoliths at the base of a laccolith. The view is from the south face of the Thaley Sagar peak. Height of the cliff is $400 \mathrm{~m}$. See view locations on Figure 2. (c) The infeeder dike system on the south face of the Shivling peak. The summit is at an altitude of $6543 \mathrm{~m}$; the foreground meadows are at $4500 \mathrm{~m}$. The summit white cliff is made of granite, the lower gray levels are orthogneisses of the HHC. In between, dark metasedimentary rocks are crosscut by a network of oblique dikes. The same dikes can also be seen in the orthogneisses but with a nearly vertical attitude. (d) A closer view of the infeeder dikes, in the Thaley Sagar west face (elevation of the cliff is $500 \mathrm{~m}$ ). North is to the right of the photo. The tilting of the dike system in the dark metasedimentary rocks indicates northward extensional shearing, preferentially located in the more ductile levels.

defined. These ratios are independent of the amount of magnetic minerals, as measured by the mean susceptibility $K_{m}$ $=\left(K_{1}+K_{2}+K_{3}\right) / 3$.

\section{Magnetic Mineralogy}

Bulk magnetic susceptibilities $\left(K_{m}\right)$ obtained on 43 samples are listed in Table 1 . The values of $K_{m}$ never exceed 50 x $10^{-6} \mathrm{SI}$, indicating that the magnetic susceptibility is dominated by iron-bearing silicates [Rochette, 1987], in particular biotite and tourmaline since the magnetic contribution of muscovite is less than $25 \%$ (a detailed discussion of magnetic properties of the Gangotri granite and other HHL is presented by Rochette et al. [1994]). Biotite and tourmaline have distinct magnetic properties: The former has the short $K_{3}$ axis of the magnetic ellipsoid being 


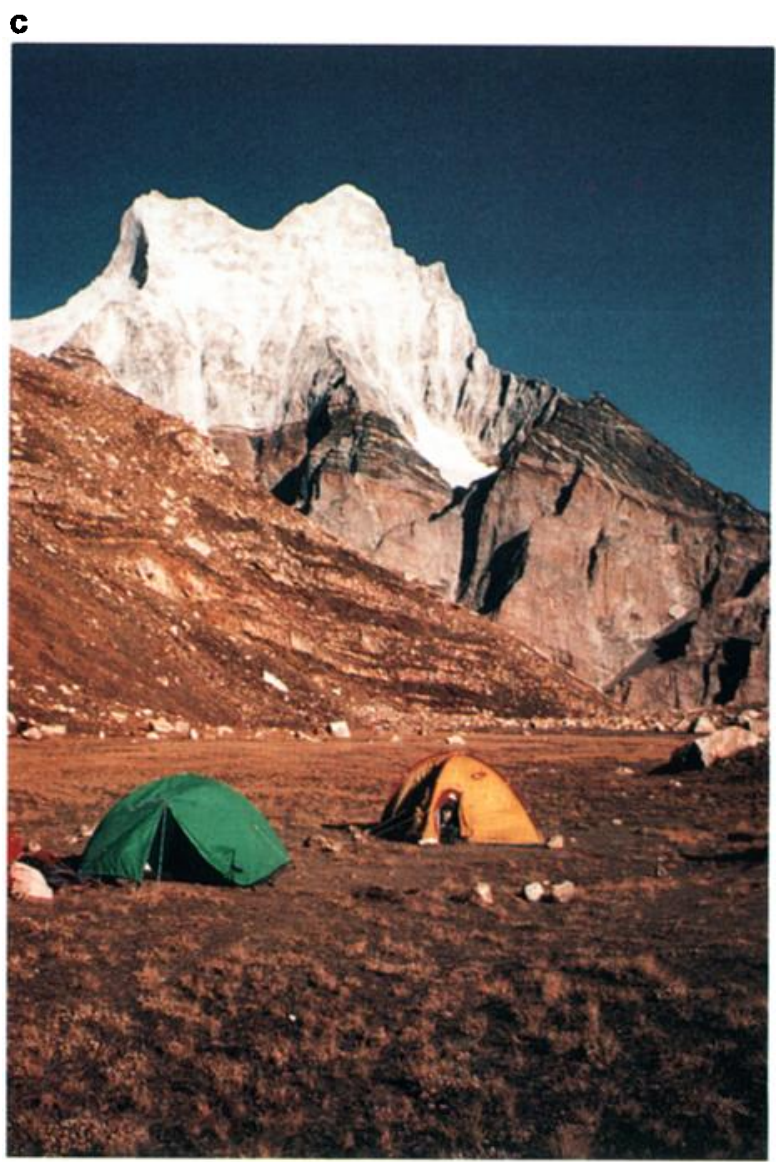

d

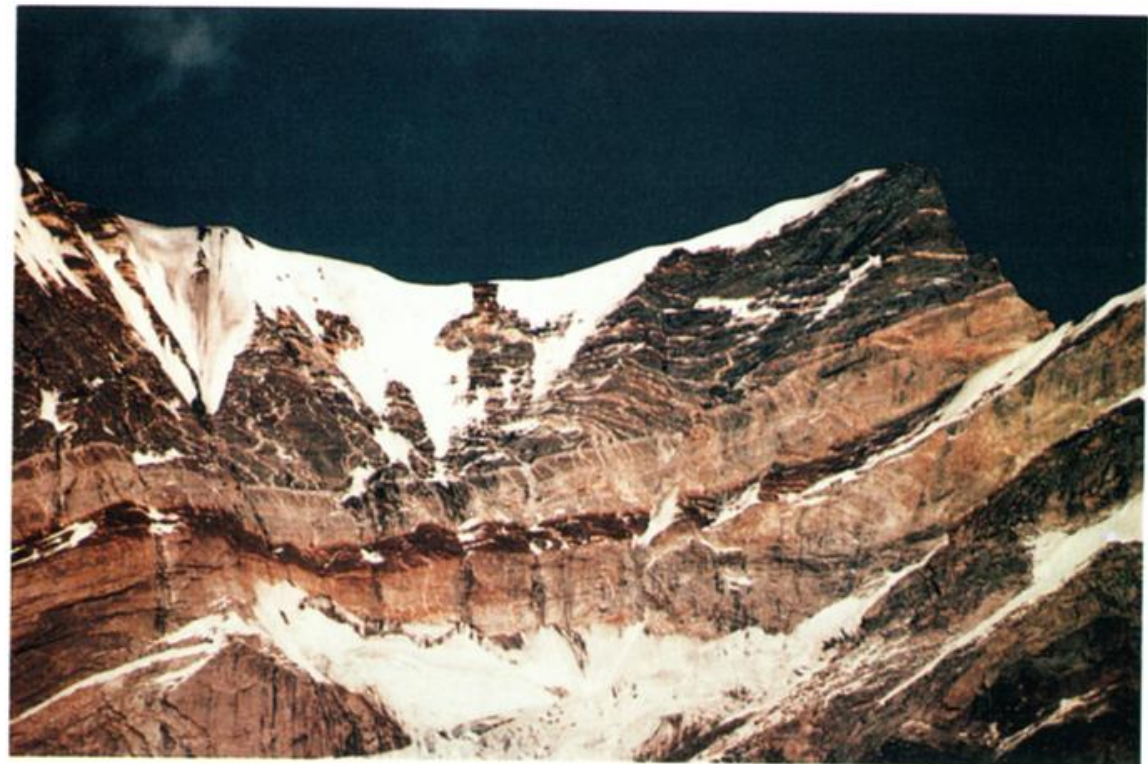

Figure 4. (continued)

perpendicular to (001) sheets and has a $P$ value of 1.35 , while the latter has an inverse fabric, $K_{3}$ being parallel to the $c$ axis of the mineral, with a $P$ value of 1.12. Thus it is important to know for each sample which mineral determines the magnetic fabric. Observations of thin sections show that 20 samples contain biotite predominant over tourmaline, 19 are tourmaline dominant, and 4 have an equal proportion of tourmaline and biotite. For the first two categories, the interpretation of magnetic directions is straightforward, with $K_{3}$ as the foliation pole in the biotite facies and $K_{3}$ as the lineation pole in the tourmaline facies. For the third case, the magnetic interaction between tourmaline and biotite give rise 


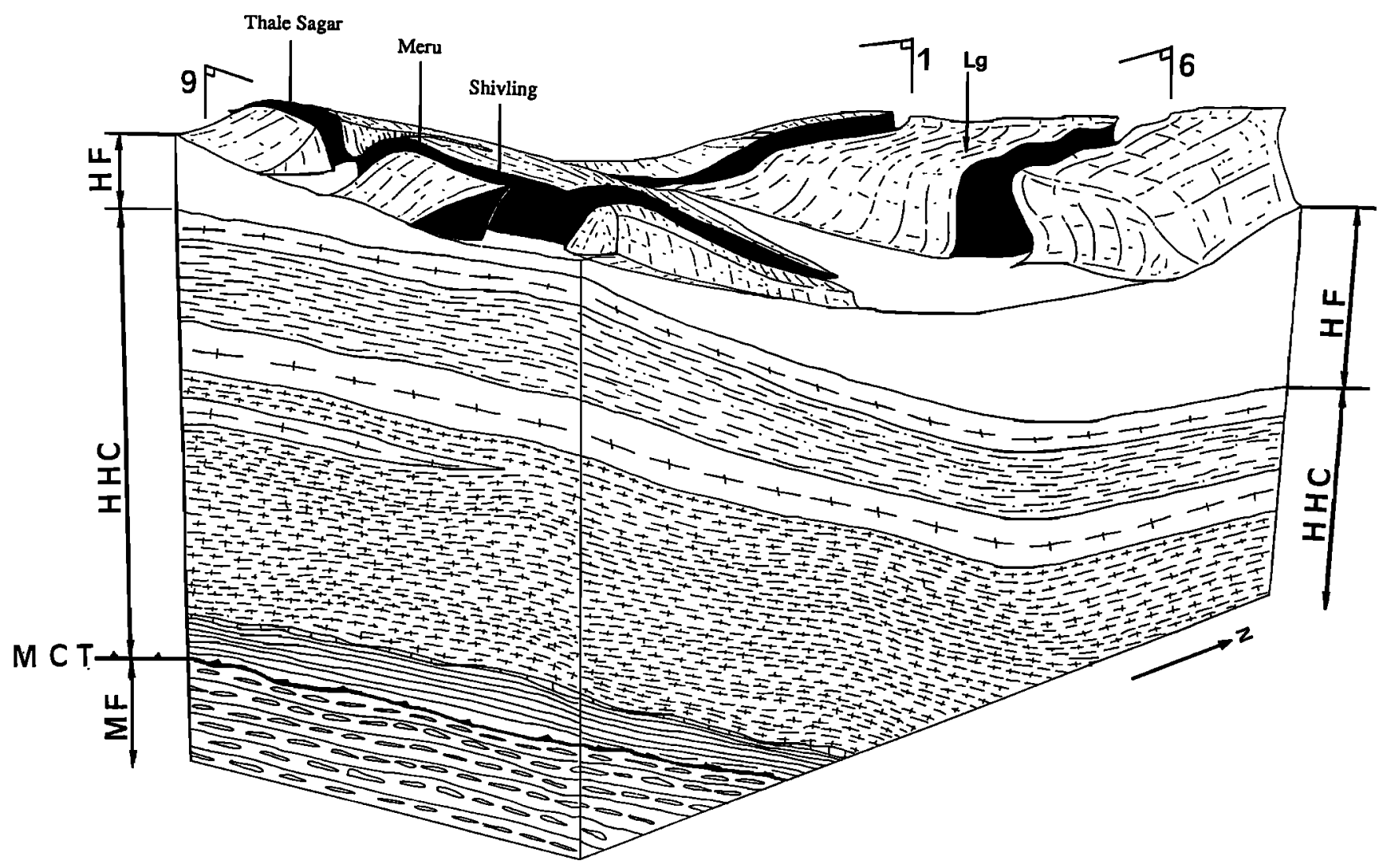

Figure 5. Block diagram of the area located between the Thaley Sagar-Meru-Shivling peaks, the northern contact of the BG granite (not shown) and bound at the east by a late dextral fault (see Figure 2), showing the 3$\mathrm{D}$ geometry of the laccoliths. The leucogranite intrusions are shown in solid areas. The large horizontal crosses represent the orthogneisses of the top of the HHC. For clarity, only the metasedimentary rocks (unpatterned) below the base of the granite are represented. The location of cross sections 1, 6, and 9 (Figure 6) is shown. The approximate positions of the Thaley Sagar, Meru and Shivling peaks are also shown. Note the position of the two main "constriction" zones discussed in the text. The distance between the bottom of the leucogranite and the MCT is around $9-10 \mathrm{~km}$, and the thickness of the thicker laccolith about $2 \mathrm{~km}$. HF, Harsil formation; HHC, High Himalayan Crystalline; MF, Midland formations; Lg, leucogranite.

to either an isotropic magnetic fabric (GB109, GB119) or is dominated by tourmaline (GB114, GB141).

\section{Directional Data}

All but two biotite-rich samples (Figure 10a) are characterized by strong $K_{1}$ and $K_{3}$ axis preferential orientations (i.e., well-defined magmatic foliation). None of these display axial zoning (i.e., lineation, but no foliation). Some samples (e.g., GL14) have a significant dispersion of the magnetic lineation $\left(K_{1}\right)$, which is not clearly correlated with its relative position in the granite lens. Even when $K_{1}$ axis defines a sharp cluster, large variations in its direction can be observed over short distances (e.g., GL15 and GL16 or GL88 and GL89, Figure 10a). Samples GB132 and GB137, both close to the bottom contact of the lens, display the strongest plastic strain structures which correlate with welldefined magnetic fabrics. Nonetheless, GB137 is characterized by a well-defined cluster of the $K_{1}$ axes, whereas GB132 has $K_{1}$ axes that are dispersed in the magnetic foliation. This shows that even in "strongly" strained samples, the stretching direction does not display a constant azimuth at the map scale.

Tourmaline-rich samples (Figure 10b) are globally characterized by a weaker fabric in comparison to biotite-rich samples (8 samples are magnetically isotropic). This feature may be a consequence of tourmaline-rich samples being more coarse-grained and thus have a lower number of tourmaline grains per core. Nonetheless, for samples with a number of cores greater than 5 , the tensorial average has still been considered as the direction of the magnetic lineation. With this in mind, a well defined cluster in the magnetic lineation $\mathrm{K}_{3}$ is commonly observed, either combined with or independent of a clustering of $\mathrm{K}_{1}$. In general, most samples from the inner parts of the lenses have $K_{3}$ axes bearing approximately East-West, with a low plunge. The presence or lack of magnetic lineation is not restricted to a given zone of the granite (e.g., GL79 and GL80, or GB4 and GB11, Figure 10b).

\section{Quantitative Data}

Most of the biotite-rich samples close to the border of the lenses clearly fall in the field of flattening (i.e., F $>L$ ), whereas samples in inner positions plot near the line $L=F$, but with very low values of $L$ and $P$. The T/P (Figure 11) diagram shows that the magnetic ellipsoid becomes 

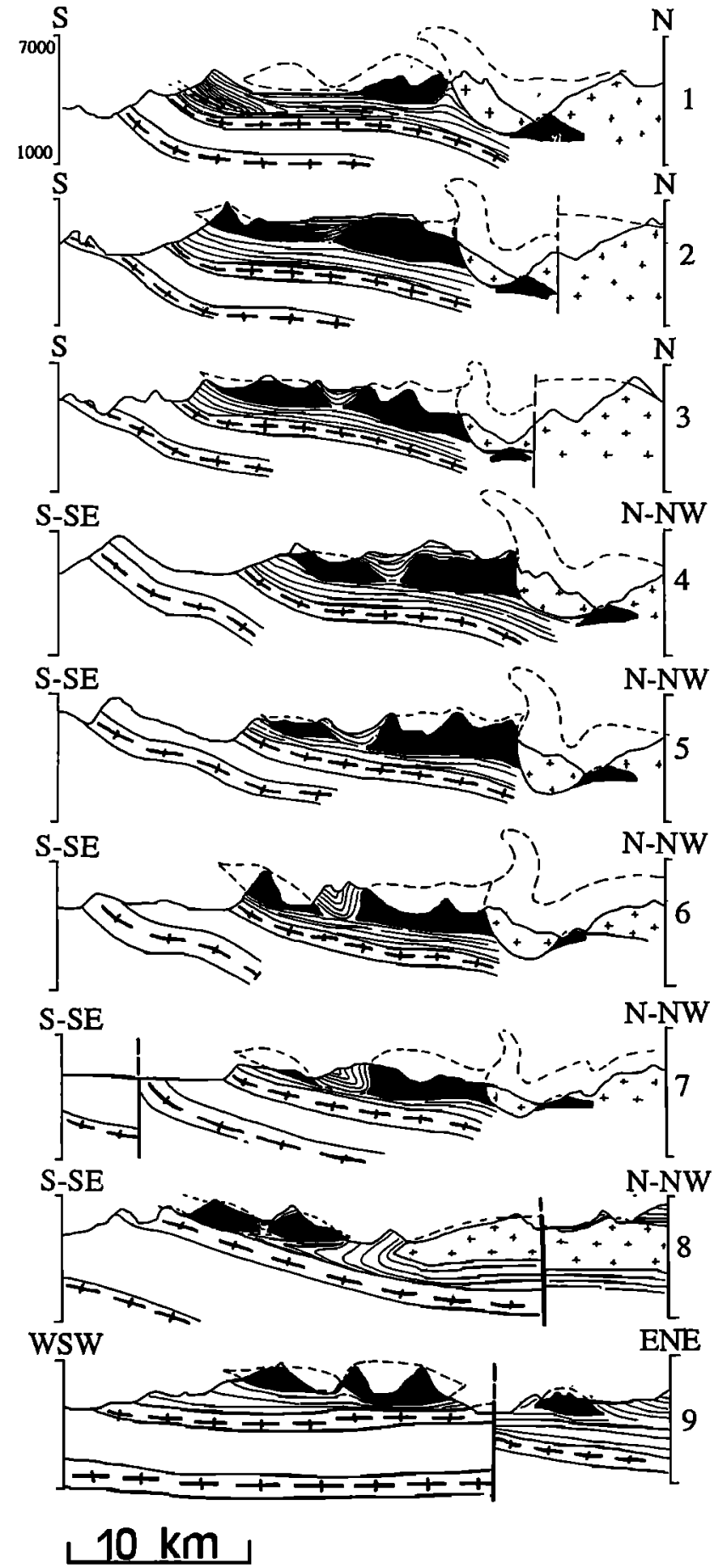

Figure 6. Cross sections across the Gangotri lenses showing the evolution of the laccolith geometry (located in Figure 2). Solid areas: leucogranite; crosses, BG granite; horizontal crosses, orthogneisses of the top of the HHC. Note the progressive evolution of the granitic lenses from west (section 1) to east (section 7). On cross section 1, a large collapse fold as viewed on the field is illustrated. See text for explanation. No vertical exaggeration.

progressively more prolate $(T>0)$ as anisotropy $(P)$ increases, with the samples closest to the lens contacts having the highest $\mathrm{T}$ and $\mathrm{P}$ values. Despite this general relation, at a scale of a few tens of meters the $P$ parameter may either increase
(GL88 to GL89) or decrease (GL16 to GL15) in relation to distance from the contact (Table 1). In addition, no correlation is observed between shape parameters and the distance of the samples from the basal or apical contacts.

Tourmaline-rich samples plot near the $L=F$ line or in the constriction field (Figure 11). On the T/P diagram, the large variation observed for $T$ does not appear to correlate with variation of $P$ values, although samples with higher $P$ values have more oblate $(T>0)$ magnetic ellipsoids. However, because of the very low anisotropy, apparent evolutions may not be significant. In contrast to biotite facies, the tourmaline samples are characterized by a general increase of $F$ and $P$ with distance from apical or basal contacts (Figure 12).

To summarize, magnetic results confirm field observations: (1) Magnetic foliations are better developed toward the borders of the lenses. A very broad E-W linear fabric exists in most of the samples from lens cores, which may be an artifact of the peripheral position of the biotite-rich samples relative to those of tourmaline. (2) Drastic changes in the direction, in the magnitude of the magnetic parameters, or in the fabric type (planar or linear), may take place over very short distances. Furthermore, the decrease observed in the $P$ parameter with distance from the contact (in the northern lenses) indicates that late magmatic deformation was not concentrated at the granite border.

\section{Strain Regime Determination Method}

The AMS does not give information about the strain regime (rotational or nonrotational), and most of the criteria used in plastically deformed rocks (e.g., C-S fabrics, lattice preferred orientations, etc.) are no longer appropriate when dealing with magmatic fabrics. However, recent studies have shown that the synmagmatic strain regime can be inferred from the shape preferred orientation (SPO) of magmatic minerals [e.g., Fernandez et al., 1983; Blumenfeld and Bouchez, 1988; Benn and Allard, 1989; Nicolas, 1992]. The interpretation of SPO is based on models of rigid particle rotation embedded in a viscous medium [Willis, 1977; Fernandez, 1987; Fernandez and Laporte, 1991; Ildefonse et al., 1992], with special emphasis on the differences in the rotation rate of particles of different shapes.

The Gangotri granite lacks K-feldpspar megacrysts, which are commonly used to infer magmatic strain [e.g., Blumenfeld and Bouchez, 1988]. Plagioclase does not occur as automorphous crystals and yields unambiguous results only in two samples. Thus micas and tourmaline were used. Only three samples provided a sufficient number of crystals of tourmaline to yield a statistically meaningful SPO fabric. Muscovite and biotite commonly have the same axial ratio, but biotite was predominantly used since it yielded well-contrasted images suitable for analysis. The data were acquired with an interactive image analyzer system [Lapique et al., 1988]. Minerals, observed in thin sections (generally two perpendicular sections for a given sample), are assimilated to ellipses. The probability density function for the orientation is then computed and characterized by the mode of the histogram of particle orientations, corresponding to a frequency $D_{m}$.

\section{Results}

The data obtained for 19 samples are listed on Table 2. Muscovite has a remarkably constant axial ratio of around 4 


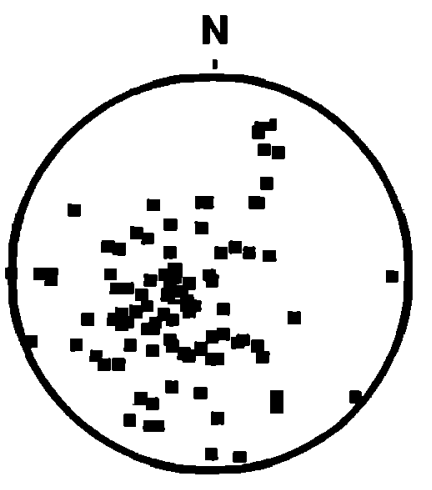

A

poles of magmatic foliations

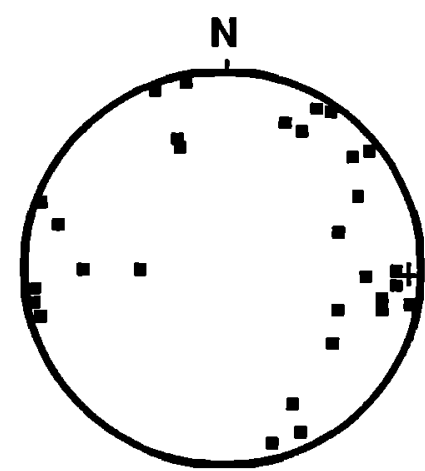

B

magmatic lineations (tourmaline)

Figure 7. Stereoplots of (a) magmatic foliation planes (93 measurements) and (b) mineral lineations ( 31 measurements). Wulff projection, lower hemisphere. The data correspond to the entire set of measurements. The crosses are the best poles of the lineation (92 E 10) and foliation (50 W 64).

(Figure 13a), whereas the axial ratios of tourmaline and biotite have larger variations, which most probably indicate differences in crystallization conditions (see below) rather than variations in the intensity of the fabric. Plagioclase is the least elongated mineral with an axial ratio ranging between 2 and 3 . The intensity of the SPO fabric $\left(D_{m}\right)$ obtained from two perpendicular thin sections in a given sample can differ significantly. For the biotite-rich samples, when the strain of the fabric increases, this difference decreases, i.e., the planar fabric becomes predominant over the linear fabric (Figure 13b). Such an evolution is also demonstrated by the clear positive correlation of $D_{m}$ with the magnetic parameter $P$ (Figure 13c). This in turn testifies to the fact that the biotite is the main magnetic mineral in the analyzed samples (note that due to the presence of tourmaline, a direct $P / D_{m}$ equivalence would underestimate the actual $\mathrm{D}_{\mathrm{m}}$ value).

In some samples it was possible to analyze two populations of markers (e.g., biotite-tourmaline, muscovitetourmaline, or plagioclase-muscovite). Figure 14 illustrates the contrast in the evolution of different markers with the strength of the deformation (indicated by the value of $D_{m}$ ): at low strain, markers with small axial ratios have a lower $D_{m}$ than markers with high axial ratios, a tendency that inverts when the strain increases. This is clearly reflected in the progressive changes of the slopes of the tie lines linking values of a given sample. Such an evolution is easily explained by the fact that minerals with higher axial ratios (e.g., biotite), rotate less. Thus, at a low strain, two contrasting populations of markers (in the same sample) will display roughly the same value of $D_{m}$, but when the strain increases, thick markers reach high values of $D_{m}$ more rapidly than thin ones. This is exemplified by the fact that the biotites rarely reach $D_{m}$ values of more than $25 \%$, whereas tourmalines commonly exceed this apparent biotite threshold. This behavior strongly suggests a nonrotational type of deformation. By comparing this to the behavior of markers observed by Fernandez et al. [1983] in simple shear experiments carried out at various values of $\gamma$ (Figure 14b), it is apparent that thick markers (i.e., with low axial ratio) attain lower $D_{m}$ values than thin markers. Finally, it is important to note that no significant angular difference was observed between the best orientations of different sets of minerals in a given sample, a fact that also indicates coaxial deformation [see Bouchez et al., 1987].

\section{Relations Between Crystallization and Deformation}

The above interpretation uses average axial ratios which mask any initial dispersion of a given mineral population [see Ildefonse et al., 1990], for example, in sample GB112, biotite axial ratios range from 1.5 to 14.5 . In magmatic rocks, apart from section effects, the timing of mineral crystallization can control the axial ratio variations. Petrographic and geochemical analyses [Scaillet et al., 1990] show that the HHL have protracted crystallization histories with biotite and tourmaline being earlier than alkali feldspar. The temperature interval of crystallization depends on the mafic character of the bulk composition [Scaillet et al., 1991]. For instance, Scaillet et al. [1991] have shown that biotite crystallization temperatures range from $770^{\circ} \mathrm{C}$ for a biotite-rich composition to less than $700^{\circ} \mathrm{C}$ in a tourmaline-rich composition. By contrast, muscovite crystallizes below $680^{\circ} \mathrm{C}$ for both compositions (with a solidus at $640-650^{\circ} \mathrm{C}$ ). Thus the amount of strain recorded by a given type of mineral can vary between compositionally different samples. Moreover, in a given sample, minerals crystallizing at different times during granite emplacement will record variable durations of deformation (e.g., biotite in mafic samples will always record more strain than muscovite but less than tourmaline in most leucocratic samples). Considering a noncoaxial strain regime,

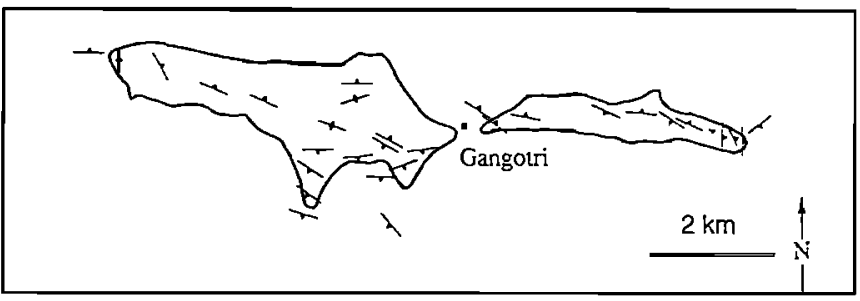

Figure 8. Finite strain in the Gangotri leucogranitic lenses, illustrated by the magmatic foliation trajectories. Note the sigmoidal pattern, which, at the map scale, intersect the contacts of the lens. Note also that at both lenses extremities, the foliation of the host rock (BG granite) is nearly perpendicular to that of the leucogranite. 


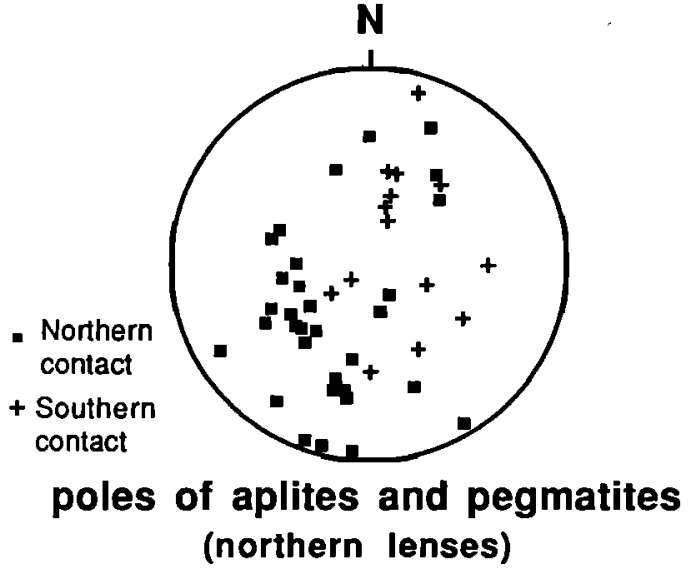

Figure 9. Orientation of aplites and pegmatites dikes in the northern lenses. Wulff projection, lower hemisphere, 37 measurements. See text.

the SPO fabric developed by early biotites can reach its own critical $\gamma\left(\gamma_{c}\right.$ of Fernandez [1987]), after which the SPO starts to be disrupted, whereas late biotites as well as other late crystallizing minerals (e.g., muscovite) are not yet oriented. In this case, the total amount of strain recorded by the biotite SPO will then be underestimated (loss of strain memory, see Hutton [1988]). If operative, this mechanism can lead to isotropic SPO biotite fabrics coexisting with anisotropic SPO fabrics of late crystallizing minerals, a feature that was not observed in our samples. Conversely, if the strain regime is coaxial during the course of crystallization, an early SPO fabric does not disappear but rather increases with time. In this case, the accuracy of the SPO will be controlled mainly by the initial aspect ratio of the minerals considered and the timing of their crystallization. For example, in samples GB170 and GB171 muscovite and tourmaline have the same axial ratio (Figure 14a) but display contrasting SPO fabrics. Petrographic and experimental work [Scaillet et al., 1990, 1991] show that tourmaline can crystallize before muscovite in these leucogranites. Thus the rather ill-defined muscovite SPO is a consequence of its late crystallization, whereas the strong SPO tourmaline fabric results from its earlier crystallization. This type of behavior also suggests a noncoaxial strain regime during granite emplacement.

It can therefore be concluded that the fabric of the granite was largely controlled by a coaxial strain regime. This is in agreement with the lack of a dominant stretching direction and with the spatial distribution of country rock xenoliths, which point to an injection mechanism with no rotational component.

\section{Discussion}

Tectonic Environment During the Emplacement of the Northern and Southern Lenses

In the country rock of the northem lenses there is a strong and penetrative E-W reorientation of the former syn-MCT fabric, which has been attributed to an E-W dextral shear zone at the top of the HHC [Pêcher and Scaillet, 1989; Pêcher, 1991]. Although the northern lenses are only weakly deformed, they clearly display a planar fabric, oriented E-W and steeply dipping. As a first approximation, this together with the overall geometry of the lenses suggest a pull-apart emplacement along a dextral shear zone. Such a mechanism has already been proposed for other plutons (e.g., Mortagne pluton [Guineberteau et al., 1987]; Central Extremadura Batholith [Castro , 1986]; Manaslu pluton [Guillot et al., 1993]) and is consistent with the NNW orientation of the finegrained granitic dikes near Harsil (representing late NNW-SSE extension cracks associated with the E-W shear zone). However, the en echelon occurrence of these dikes clearly indicates that this shear zone also acted as a normal fault, which in turn suggests that granite emplacement was favored by an extensional tectonic regime. Thus the magmatic fabric of the northern lenses resulted from a combined dextral and normal movement of this shear zone. However, it is important to note that the fabric records only a magmatic stage (no plastic strain) and that near the pluton borders, the fabric is not parallel to that of the host rocks. These observations imply that emplacement occurred late in this dextral and normal shearing zone, in agreement with the lack of helicoidal flattening fabric in the Gangotri granite and with the lack of strain neutral points in the host rocks [see Brun and Pons, 1981]. It follows that this shear zone was probably not the major factor controlling the "space" necessary for magma intrusion, as Hutton et al. [1990] suggested for rapakivi granite in Greenland.

The southern lenses are characterized by a dispersion of the mineralogical or magnetic lineations which contrasts markedly with the well-defined E-W preferred orientation of the stretching lineation in the surrounding metasedimentary rocks [Pêcher and Scaillet, 1989; Jain and Anand, 1988]. Furthermore, there is no continuity between metamorphic and magmatic foliations, as for the northern lenses. It can be concluded that granite emplacement occurred after the deformation that was associated with the main metamorphic event, coeval with MCT shear deformation. Since the granite crosscuts late to postmetamorphic north vergent collapse folds at an outcrop scale but its eastern prolongation (the Badrinath granite) is crosscut by the extensional Malari fault [Hodges and Silverberg, 1988], granite emplacement must have occurred during the extensional tectonic phase.

Therefore it appears that the northern and southern lenses were emplaced in two different tectonic environments. A very late emplacement in a zone affected by an E-W trending shear zone with both a dextral and normal component can be inferred for the northern lenses. By contrast, the southern lenses intruded in a zone where an extensional tectonic regime prevailed. This regional stress field agrees well with the mesofabrics displayed by the granite (lack of dominant streching direction) as well as with the strain regime inferred from the SPO analysis (coaxial strain regime). Given that both the extensional and dextral shear tectonics are late metamorphic and structural features in the Himalayan orogenic evolution, an important question is whether these leucogranites are genetically linked to the southward crustal stacking along the MCT.

\section{Are These Leucogranites Thrust (MCT)-Related Magmas?}

The most popular model for HHL melt generation to date is that of Le Fort [1975, 1981] in which the onset of melting is governed by fluid infiltration at the time of MCT shearing which led to the crustal thickening. Thermal modeling carried out by Molnar and England [1990] and England et al. [1992] show that this model is indeed viable if shear heating is taken 


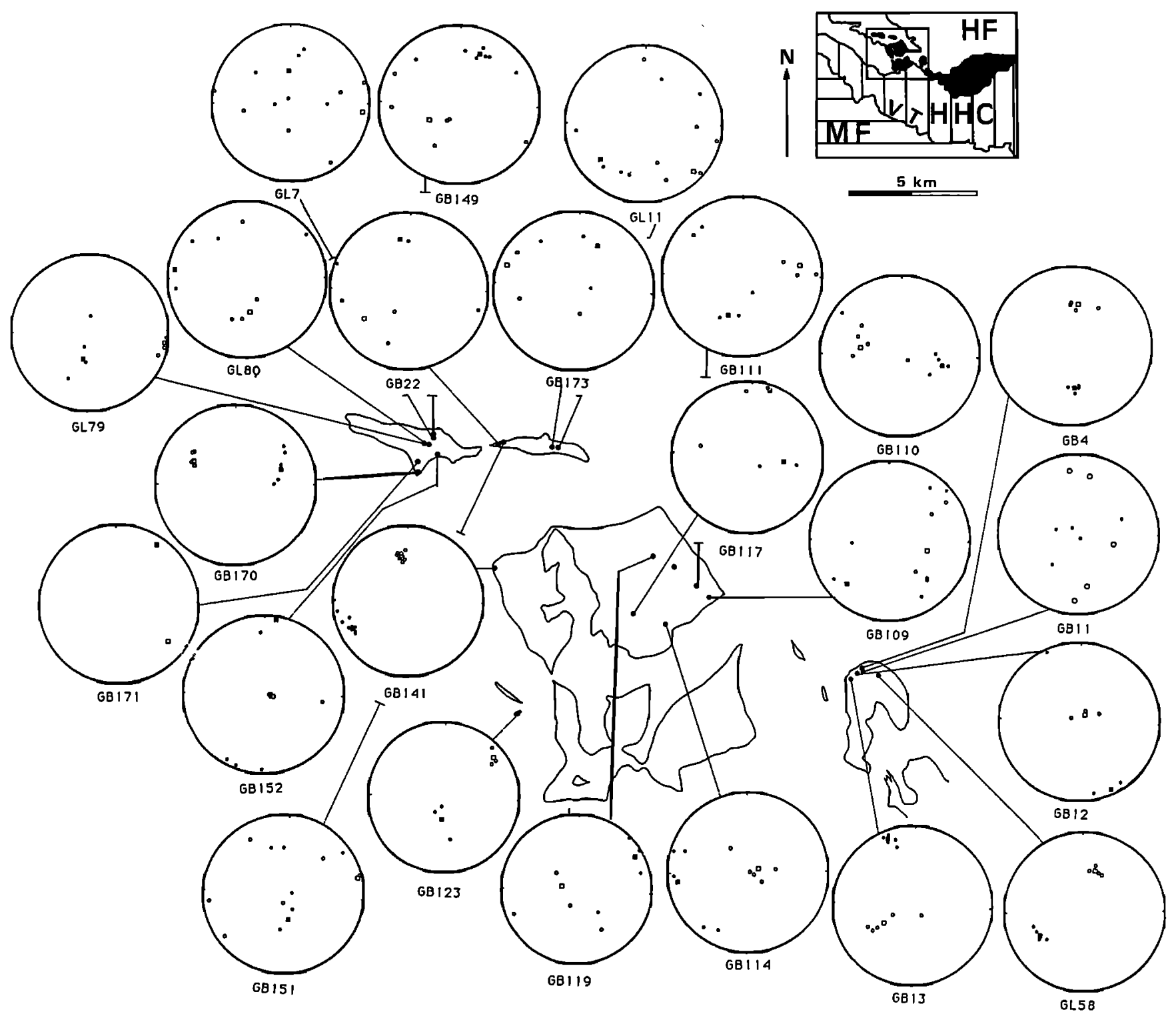

Figure 10a. Magnetic fabric in the leucogranitic lenses for biotite-rich samples. The numbers refer to the samples, Table 1 and in the text. Solid symbols, $K_{1}$; open symbols, $K_{3}$. The squares refer to the tensoriel average of the values obtained on one sample.

into account. Note that models based on in situ generation of . the melt in the higher part of the metamorphic pile [Jaupart and Provost, 1985; Pinet and Jaupart, 1987] are to be excluded here as the Gangotri lenses are clearly allocthonous. Therefore, if the model of Le Fort is applicable to the Gangotri lenses, then the melt generation was syn-MCT.

How granitic magma ascends through the crust is a recurring problem, mainly because direct field evidence is generally not available. However, the area investigated is unique in that the upper part of the overall migration path is exposed along nearly $1000 \mathrm{~m}$ of vertical cliff (Figure 4). The well-displayed dike system beneath the granitic lenses decisively shows that the mechanism of ascent of the magma was by fracture propagation. Vertical orientation of the dikes indicates that the maximum principal compressive stress was nearly vertical at the time of their emplacement. Even if the stress orientation of the crust was different with depth, we see no reasons to call for a mechanism other than that of fracture ascent at deeper crustal levels. All HHL investigated so far are characterized by strong $\mathrm{Rb} / \mathrm{Sr}$ heterogeneities at all scales [see Le Fort et al., 1987; Deniel et al., 1987], presumably reflecting an initial heterogeneity of the metasedimentary source (the HHC). To explain such heterogeneities, Deniel et al. [1987] suggest a feeding of the granitic body through successive individual small batches of magma which, because of the inferred high viscosity of hyper siliceous liquids [e.g., Wickam, 1987], remained unmixed. As noted by Clemens and Mawer [1992], such a mechanism of pluton growth is entirely consistent with a fracture mode of ascent for a granitic magma which preserves source inherited heterogeneities. Therefore the fracture ascent mechanism appears to be the dominant mode of granitic magma transport throughout plurikilometric crustal sections for the Gangotri plutons as well as for other HHL plutons. Note, however, that these dikes are younger than the metamorphic foliation (which is syn-MCT), thereby indicating a lag time between magma generation (syn-MCT) and ascent (post-MCT).

The granites were emplaced as laccoliths, at least for the 


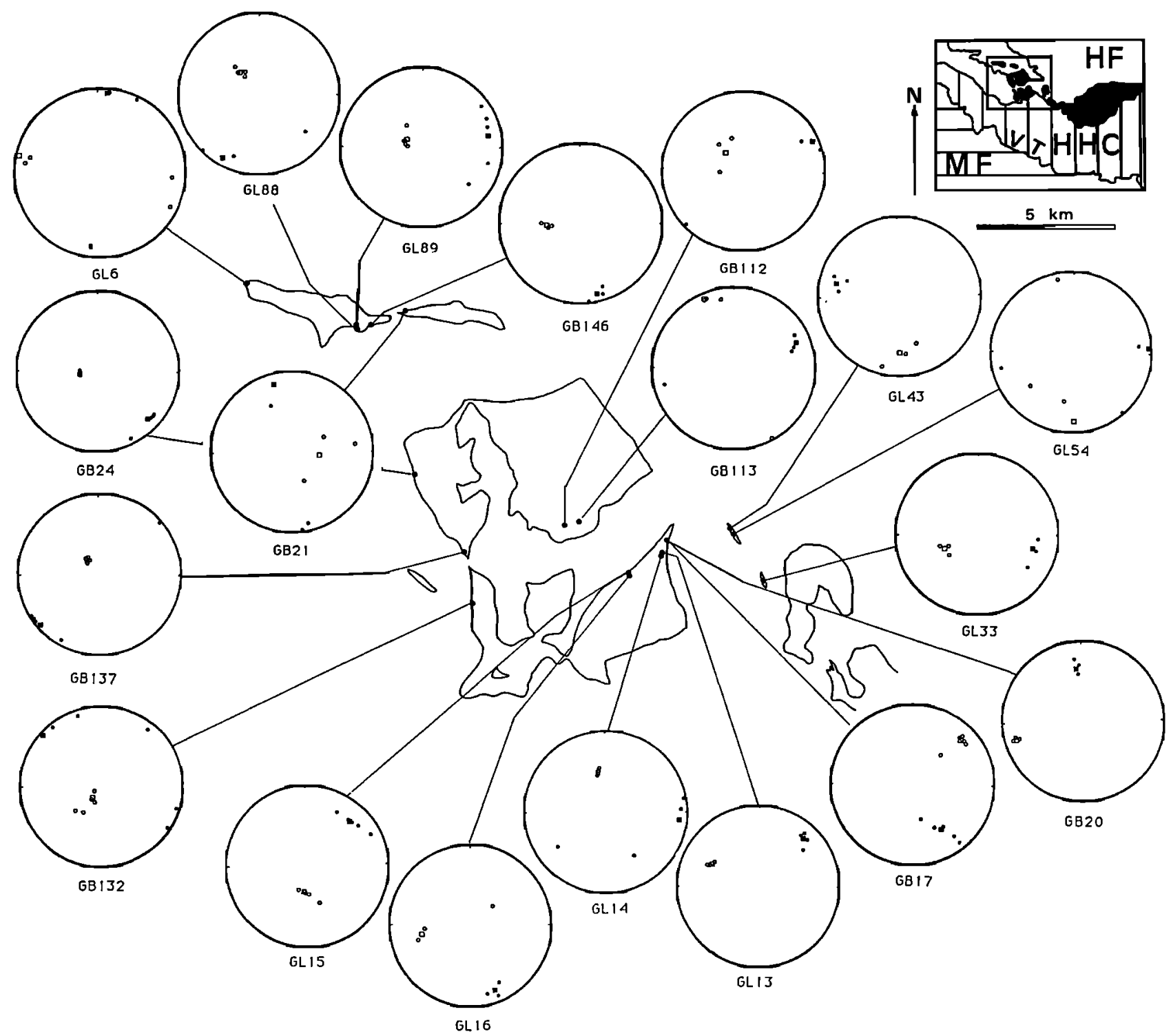

Figure 10b. Magnetic fabric in the leucogranitic lenses for tourmaline-rich and mixed samples. The numbers refer to the samples, Table 1 and in the text. Solid symbols, $K_{1}$; open symbols, $K_{3}$. The squares refer to the tensoriel average of the values obtained on one sample.

southern lenses. Now the question is: Why does the magma stop rising? An arrest of the magma due to an increase in its shear strength as a result of crystallisation should have induced balloning effects, with subsolidus structures (i.e., plastic strain) overprinting magmatic structures, especially at the edges of the pluton [Bateman, 1985]. Such features are lacking in the Gangotri granites. Thus, although rare indications of flattening associated with ballooning can be found (dikes isoclinally folded close to the top of some massifs), we infer a restricted role for this mechanism. Other mechanisms thought to be responsible for arresting the upward propagation of magma-filled fractures have been reviewed by Clemens and Mawer [1992]. They propose that the most likely cause of arrest of a propagating fracture is when the traveling tensile fracture meets a mechanical discontinuity (the Cook-Gordon mechanism). This is clearly not the case here since the level of emplacement of the southern lenses is inside the metasedimentary rocks and not at the main lithological boundary between the orthogneisses of the HHC and the metasedimentary rocks, both dipping $20-30^{\circ}$ northward (Figures 5 and 6). Therefore the emplacement level was not controlled by this mechanical discontinuity. The very flat lying floor of the southern lenses also precludes the control of the emplacement level by the intersection of the fracture-filled magma with the extensional shear zone which, in the area of interest, dips $70-80^{\circ}$ northward [Pêcher and Scaillet, 1989] and crosscuts the granite [Hodges and Silverberg, 1988]. The arrest of a magma by the attainment of its level of neutral buoyancy [Lister and Kerr, 1991], previously proposed for the Gangotri lenses by Scaillet et al. [1990], does not fit with the laccolithic shape preserved by the southern lenses. This implies that the magmatic pressure was in excess of the lithostatic pressure [Johnson and Pollard, 1973] (see below). Searle et al. [1993] have also proposed that the leucogranites were emplaced within large-scale tension gashes associated to an extensional duplex zone. However this mechanism implies a generalized noncoaxial strain, whose effects were not preserved by the current fabric 
Table1. Magnetic Susceptibility Results and Position of the Samples Within the Lenses

\begin{tabular}{|c|c|c|c|c|c|c|c|}
\hline Sample & $\mathbf{N}$ & $\underset{10^{-6} \times \mathrm{SI}}{\mathrm{K}_{\mathrm{m}}}$ & $\begin{array}{c}\mathrm{L}, \\
\mathrm{K}_{1} / \mathrm{K}_{2}\end{array}$ & $\begin{array}{c}F, \\
K_{3} / K_{2}\end{array}$ & $\begin{array}{c}P \\
K_{1} / K_{3}\end{array}$ & $\mathbf{T}$ & $\begin{array}{l}\mathrm{D} \\
\mathrm{m}\end{array}$ \\
\hline GL 6 * & 4 & 18.7 & 1.026 & 1.038 & 1.065 & 0.185 & $50(\mathrm{~s})$ \\
\hline GL 7 & 6 & 25.6 & 1.014 & 1.008 & 1.022 & -0.297 & 700 (s) \\
\hline GL 11 & 6 & 19.1 & 1.005 & 1.009 & 1.014 & 0.309 & $300(\mathrm{~s})$ \\
\hline GL $13^{*}$ & 4 & 35.5 & 1.011 & 1.078 & 1.090 & 0.744 & 50 (b) \\
\hline GL $14^{*}$ & 4 & 34.7 & 1.001 & 1.064 & 1.065 & 0.978 & 50 (b) \\
\hline GL $15^{*}$ & 5 & 32.2 & 1.014 & 1.056 & 1.071 & 0.591 & 12 (s) \\
\hline GL $16^{*}$ & 3 & 19.7 & 1.030 & 1.022 & 1.052 & -0.147 & $.5(\mathrm{~s})$ \\
\hline GL 33* & 3 & 27.9 & 1.011 & 1.021 & 1.033 & 0.297 & 50 (b) \\
\hline GL 43* & 4 & 28.3 & 1.013 & 1.009 & 1.022 & -0.183 & 5 (b) \\
\hline GL $54^{*}$ & 3 & 33.7 & 1.011 & 1.003 & 1.014 & -0.565 & 5 (b) \\
\hline GL 58 & 4 & 21.0 & 1.019 & 1.011 & 1.031 & -0.260 & 20 (s) \\
\hline GL 79 & 4 & 22.8 & 1.009 & 1.058 & 1.068 & 0.724 & 800 (s) \\
\hline GL 80 & 4 & 04.7 & 1.010 & 1.012 & 1.022 & 0.059 & 800 (s) \\
\hline GL 88* & 4 & 31.2 & 1.010 & 1.089 & 1.100 & 0.793 & 20 (s) \\
\hline GL $89 *$ & 5 & 34.2 & 1.012 & 1.062 & 1.074 & 0.677 & $80(\mathrm{~s})$ \\
\hline GB 4 & 4 & 27.4 & 1.018 & 1.029 & 1.048 & 0.228 & $250(\mathrm{~s})$ \\
\hline GB 11 & 5 & 14.1 & 1.009 & 1.013 & 1.021 & 0.200 & 250 (s) \\
\hline GB 12 & 3 & 18.5 & 1.021 & 1.014 & 1.035 & -0.217 & 150 (s) \\
\hline GB 13 & 5 & 19.4 & 1.015 & 1.012 & 1.028 & -0.117 & 200 (s) \\
\hline GB $17^{*}$ & 6 & 37.2 & 1.015 & 1.016 & 1.031 & 0.052 & 2 (b) \\
\hline GB $20 *$ & 3 & 09.9 & 1.020 & 1.040 & 1.060 & 0.339 & 4 (b) \\
\hline GB $21^{*}$ & 3 & 24.0 & 1.007 & 1.004 & 1.011 & -0.271 & $150(\mathrm{~s})$ \\
\hline GB 22 & 3 & 12.1 & 1.007 & 1.014 & 1.020 & 0.339 & 150 (s) \\
\hline GB $24^{*}$ & 4 & 43.1 & 1.005 & 1.062 & 1.067 & 0.857 & 15 (b) \\
\hline GB $109^{\dagger}$ & 5 & 24.1 & 1.004 & 1.012 & 1.016 & 0.516 & 100 (1) \\
\hline GB 110 & 5 & 17.0 & 1.011 & 1.010 & 1.021 & -0.047 & 550 (b) \\
\hline GB 111 & 4 & 20.7 & 1.007 & 1.010 & 1.017 & 0.155 & 500 (b) \\
\hline GB $112^{*}$ & 3 & 35.3 & 1.025 & 1.017 & 1.042 & -0.166 & 350 (b) \\
\hline GB $113^{*}$ & 4 & 28.1 & 1.018 & 1.038 & 1.056 & 0.349 & 350 (b) \\
\hline GB $114^{\dagger}$ & 5 & 28.9 & 1.005 & 1.012 & 1.018 & 0.397 & 700 (b) \\
\hline GB $117^{\dagger}$ & 3 & 27.8 & 1.005 & 1.004 & 1.009 & -0.132 & 500 (b) \\
\hline GB $119^{\dagger}$ & 4 & 20.8 & 1.014 & 1.004 & 1.018 & -0.573 & $400(\mathrm{~b})$ \\
\hline GB 123 & 3 & 29.1 & 1.012 & 1.025 & 1.038 & 0.333 & 1 (b) \\
\hline GB $132^{\dagger}$ & 5 & 20.7 & 1.001 & 1.022 & 1.023 & 0.896 & 20 (b) \\
\hline GB $137^{*}$ & 5 & 36.9 & 1.018 & 1.076 & 1.096 & 0.610 & 10 (b) \\
\hline GB 141 & 8 & 28.6 & 1.012 & 1.021 & 1.033 & 0.283 & 80 (b) \\
\hline GB $146^{*}$ & 3 & 33.3 & 1.010 & 1.029 & 1.039 & 0.505 & 0 (s) \\
\hline GB 149 & 7 & 23.4 & 1.016 & 1.004 & 1.020 & 0.800 & 560 (s) \\
\hline GB 151 & 6 & 16.2 & 1.004 & 1.011 & 1.015 & 0.432 & 0 (s) \\
\hline GB 152 & 4 & 09.9 & 1.013 & 1.034 & 1.048 & 0.443 & 50 (s) \\
\hline GB 170 & 6 & 22.3 & 1.010 & 1.042 & 1.052 & 0.602 & 2 (s) \\
\hline GB 171 & 5 & 27.5 & 1.006 & 1.023 & 1.029 & 0.607 & 250 (s) \\
\hline GB 173 & 3 & 24.3 & 1.007 & 1.006 & 1.013 & -0.032 & 300 (s) \\
\hline
\end{tabular}

$\mathrm{N}$, number of cores by samples; $\mathrm{K}_{\mathrm{m}}$, mean magnetic susceptibility; $\mathrm{L}, \mathrm{F}, \mathrm{P}, \mathrm{T}$, shape parameters of the ellipsoid of the magnetic susceptibility. $T=2\left(k_{2}-k_{3}\right) /\left(k_{1}-k_{3}\right)-1$, with $k_{i}=\ln \left(K_{i}\right)$. D, distance in meters from the summital (s), lateral (l) or basal (b) contact.

* Biotite rich sample,

$\dagger$ Biotite + tourmaline samples, the remaining being the tourmalines rich samples.

of the granite. Furthermore, the shape of the lenses of Figure 3 clearly does not conform to that expected from a melt being injected in active tension gashes. In the area of interest, we have been impressed by the fact that the north vergent collapse folds are preferentially located at the level of granite intrusion (see cross section 1, Figure 6) which does suggest that the level of the southern intrusion is under control of these local discontinuities. This is a mechanism whereby the traveling tensile fracture is stopped when it intersects an almost freely slipping horizontal zone [Weertman, 1980], in the present case the lower sheared limb of large-scale collapse folds (cross section 1, Figure 6). We therefore envisage that the level of granitic intrusion in the metasedimentary rocks is closely controlled by the location of the collapse folds 

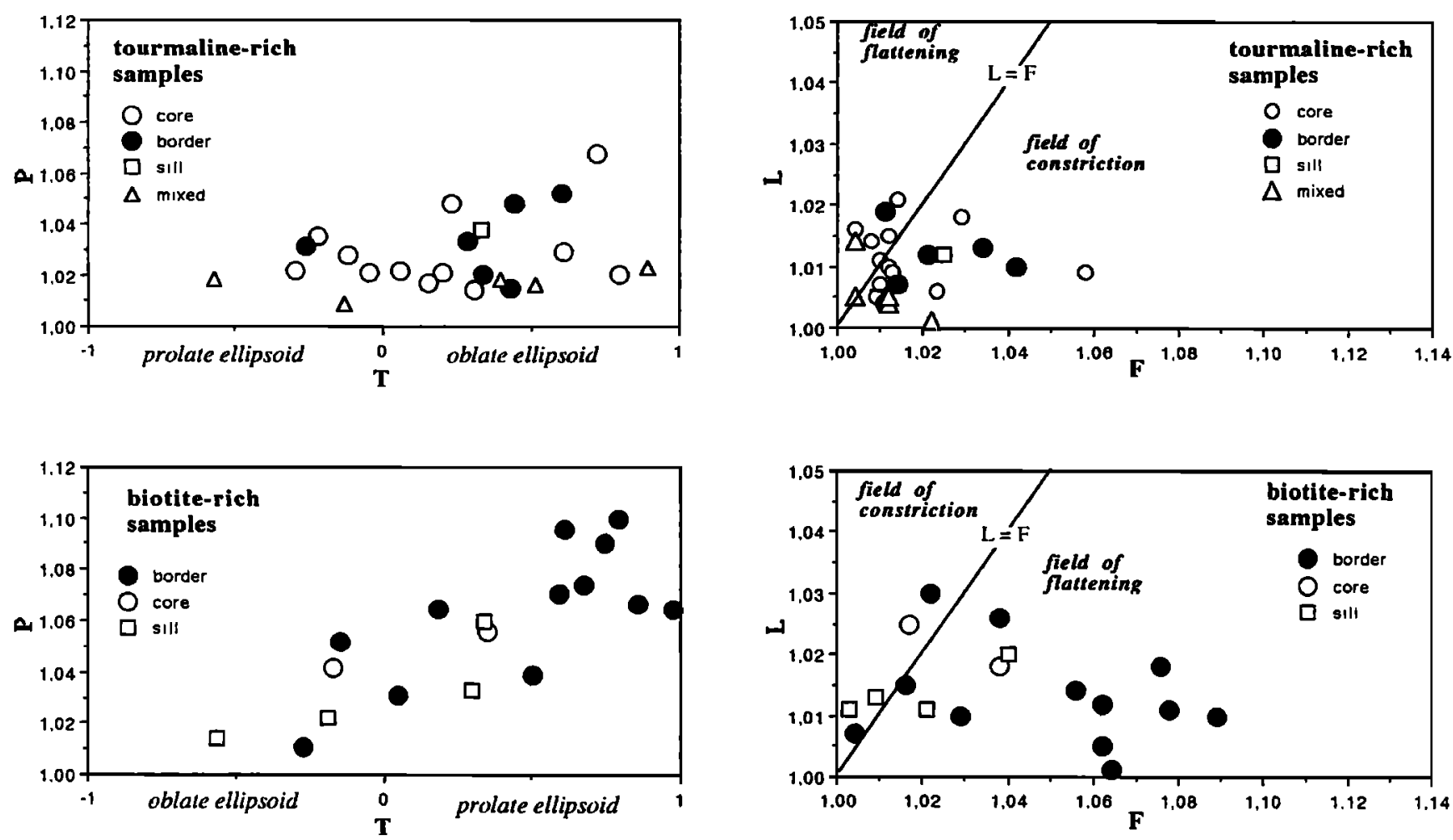

Figure 11. Shape parameters of the magnetic ellipsoid. The samples are distinguished by different symbols depending on their position (in the core of a lens or close to its border, or within a sill). Triangles plotted with the tourmaline-rich samples correspond to "mixed" samples, where tourmaline predominance is not obvious (see text).

associated with the onset of extensional tectonics. The situation is less clear for the northern lenses, because their basal contact is not exposed. However, it is important to note that the northern lenses are intruded (1) in a zone of active dextral and normal shearing and (2) in the huge BG granite. Cross sections of this area (Figure 6) show that the BG granite is also lenticular in shape with its floor corresponding to the top of the northern lenses. Therefore, in the case of the northern lenses the hypothesis of a mechanical control of the emplacement level is plausible (i.e., between the BG granite and the underlying metasedimentary rocks), but the intersection of the propagating fractures with the active shear zone may also have played a role in localizing the level of emplacement.

To summarize, the emplacement of Gangotri leucogranites is not indicative of crustal stacking along the MCT. The lenses were emplaced at the top of the HHC during the onset of an extensional deformation and along the northern dextral shear zone. It follows that the term, thrust-related magma may apply only to the generation process. Neither the ascent nor the emplacement mechanism are directly controlled by the MCT intracontinental shear zone. If the Le Fort model applies to this area, then the delay existing between magma production and emplacement may reflect the time needed to reach a critical amount of melt in the source zone before the liquid becomes mobile [Arzi, 1978; Molen and Paterson, 1979; Miller et al., 1988]. Whatever its cause, the importance of this lag time cannot be constrained based on the previous tectonic considerations: i.e., the distinction between compressional and extensional regimes exists in space but
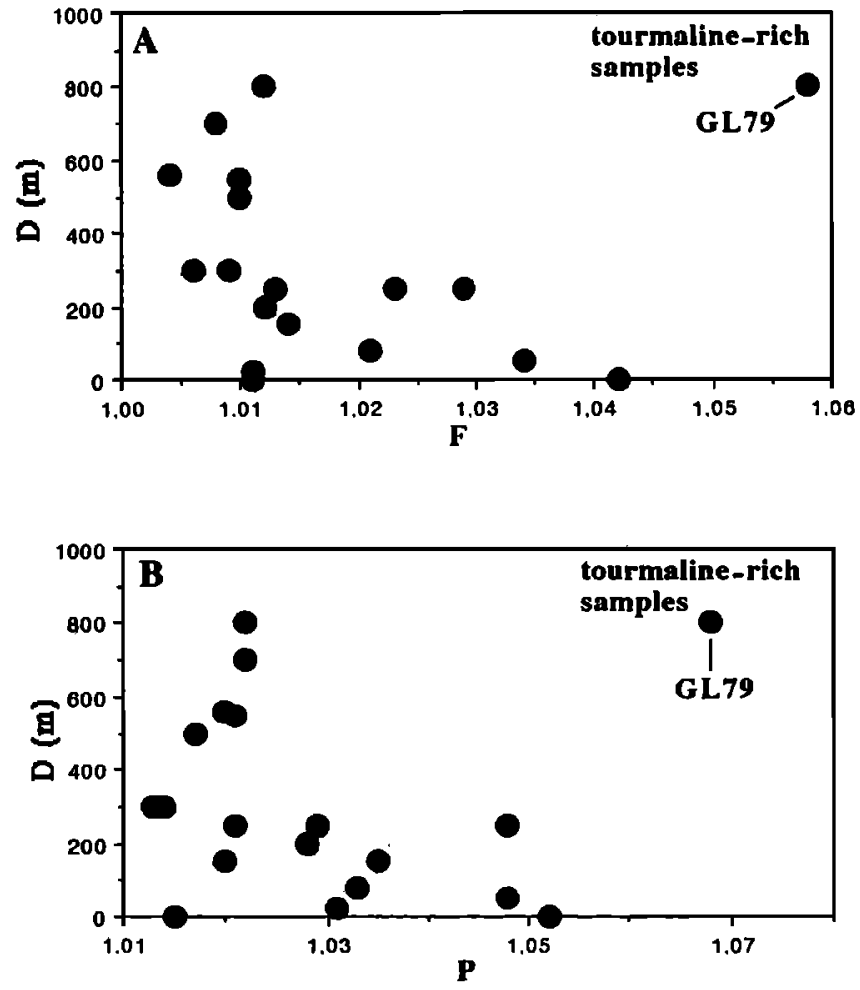

Figure 12. Shape parameters (b) $P$ and (a) $F$ of the magnetic ellipsoid in the tourmaline-rich samples, versus distance from the lens contact (D, expressed in meters, see Table 1 ). 
Table 2. Results of SPO Measurements

\begin{tabular}{|c|c|c|c|c|c|c|}
\hline \multirow[b]{2}{*}{ Sample } & \multicolumn{3}{|c|}{ Section 1} & \multicolumn{3}{|c|}{ Section 2} \\
\hline & $\mathrm{D}_{\mathrm{m}}$ & Axial Ratio & $\mathbf{N}$ & $\mathbf{D}_{\mathrm{m}}$ & Axial Ratio & $\mathbf{N}$ \\
\hline & \multicolumn{6}{|c|}{ Biotite } \\
\hline $\begin{array}{l}\text { GB17 } \\
\text { GB21 } \\
\text { GB24 } \\
\text { GB112 } \\
\text { GB113 } \\
\text { GB132 } \\
\text { GB137 } \\
\text { GB146 } \\
\text { GL13 } \\
\text { GL14 } \\
\text { GL15 } \\
\text { GL33 } \\
\text { GL54 } \\
\text { GL88 } \\
\text { GL89 }\end{array}$ & $\begin{array}{l}11.6 \\
12.3 \\
17.2 \\
25.1 \\
16.9 \\
18.8 \\
20.5 \\
17.4 \\
16.3 \\
17.2 \\
18.4 \\
12.1 \\
11.6 \\
20.2 \\
18.5\end{array}$ & $\begin{array}{l}5.0 \\
4.2 \\
5.2 \\
5.2 \\
6.0 \\
6.4 \\
5.6 \\
4.0 \\
4.2 \\
5.2 \\
7.0 \\
4.6 \\
4.2 \\
5.3 \\
4.3\end{array}$ & $\begin{array}{c}216 \\
172 \\
222 \\
122 \\
101 \\
167 \\
106 \\
124 \\
201 \\
183 \\
198 \\
87 \\
201 \\
137 \\
249\end{array}$ & $\begin{array}{c}- \\
- \\
14.2 \\
- \\
15.1 \\
14.7 \\
19.6 \\
14.7 \\
11.8 \\
18.5 \\
15.9 \\
11.2 \\
- \\
- \\
17.7\end{array}$ & $\begin{array}{c}- \\
- \\
5.2 \\
- \\
7.1 \\
6.5 \\
5.6 \\
3.9 \\
3.5 \\
4.9 \\
7.4 \\
4.8 \\
- \\
- \\
4.5\end{array}$ & $\begin{array}{c}- \\
- \\
217 \\
- \\
168 \\
205 \\
183 \\
176 \\
113 \\
123 \\
193 \\
113 \\
- \\
- \\
105\end{array}$ \\
\hline GL89 & \multicolumn{6}{|c|}{ Muscovite } \\
\hline \multirow[t]{2}{*}{$\begin{array}{l}\text { GB113 } \\
\text { GB170 } \\
\text { GB171 } \\
\text { GL79 }\end{array}$} & $\begin{array}{l}14.4 \\
24.8 \\
19.7 \\
15.3\end{array}$ & $\begin{array}{l}4.0 \\
4.0 \\
4.0 \\
3.9\end{array}$ & $\begin{array}{l}101 \\
157 \\
208 \\
145\end{array}$ & $\begin{array}{c}17.4 \\
18.3 \\
14.2 \\
-\end{array}$ & $\begin{array}{c}3.6 \\
3.2 \\
3.7 \\
-\end{array}$ & $\begin{array}{c}149 \\
117 \\
163 \\
-\end{array}$ \\
\hline & \multicolumn{6}{|c|}{ Tourmaline } \\
\hline \multirow[t]{2}{*}{$\begin{array}{l}\text { GB } 132 \\
\text { GB170 } \\
\text { GB171 }\end{array}$} & $\begin{array}{l}18.3 \\
26.8 \\
31.0\end{array}$ & $\begin{array}{l}1.8 \\
3.2 \\
2.4\end{array}$ & $\begin{array}{c}61 \\
143 \\
40\end{array}$ & $\begin{array}{c}21.9 \\
32.5 \\
-\end{array}$ & $\begin{array}{c}2.0 \\
3.6 \\
-\end{array}$ & $\begin{array}{c}68 \\
217 \\
-\end{array}$ \\
\hline & \multicolumn{6}{|c|}{ Plagioclase } \\
\hline \multirow[t]{2}{*}{$\begin{array}{l}\text { GB24 } \\
\text { GL79 }\end{array}$} & $\begin{array}{l}12.4 \\
13.8\end{array}$ & $\begin{array}{l}2.5 \\
2.1\end{array}$ & $\begin{array}{l}111 \\
112\end{array}$ & - & - & - \\
\hline & \multicolumn{6}{|c|}{ Experiments From Fernandez et al. [1983] } \\
\hline $\begin{array}{l}\text { FER(0.0) } \\
\text { FER(2.5) } \\
\text { FER(4.0) } \\
\text { FER(5.5) }\end{array}$ & $\begin{array}{l}14.2 \\
23.5 \\
28.0 \\
26.6\end{array}$ & $\begin{array}{l}5 \\
5 \\
5 \\
5\end{array}$ & $\begin{array}{l}49 \\
47 \\
50 \\
49\end{array}$ & $\begin{array}{l}15.2 \\
25.5 \\
23.5 \\
22.5\end{array}$ & $\begin{array}{l}2 \\
2 \\
2 \\
2\end{array}$ & $\begin{array}{l}46 \\
51 \\
51 \\
49\end{array}$ \\
\hline
\end{tabular}

For natural samples, sections 1 and 2 represent two perpendiculars thin sections which are orthogonal to the magmatic or magnetic foliation. For the experiments, the number in parentheses indicates the amount in simple shear realised in the run and the data reported in sections 1 and 2 belong to the same experiment. $D_{m}$ : maximum in percent in the histogram of distribution of the long axis for each subfabric measured in one plane. $\mathrm{N}$, number of digitized minerals.

not necessarily in time, as the two corresponding stress regimes can be contemporaneous in a convergent orogen [Burchfield and Royden, 1987]. For instance, the gravitational instability leading to extension at the top of the HHC can be explained by a ramp effect during the southward motion of the MCT [e.g., Caby et al., 1983; Burg et al., 1984].

\section{Laccoliths or Crustal Scale Boudins?}

The general pattem of the southem lenses, as well as the mesoscopic structures (i.e., lack of dominant streching direction), led Scaillet et al. [1989] to suggest that these lenses may have derived from a single initial larger laccolith affected by a crustal scale boudinage (see also Searle et al. [1993]), instead of representing independent laccoliths. The resulting overall geometry is a "tablette de chocolat" pattern, with two majors constrictional trends, a north-south one and a more prominent east-west one (Figure 5). The amount of overload needed for flattening is supported by recent detailed thermobarometric investigations carried out in the Badrinath area by Hodges and Silverberg [1988]. They have shown that the metamorphic evolution at the level of granite intrusion 

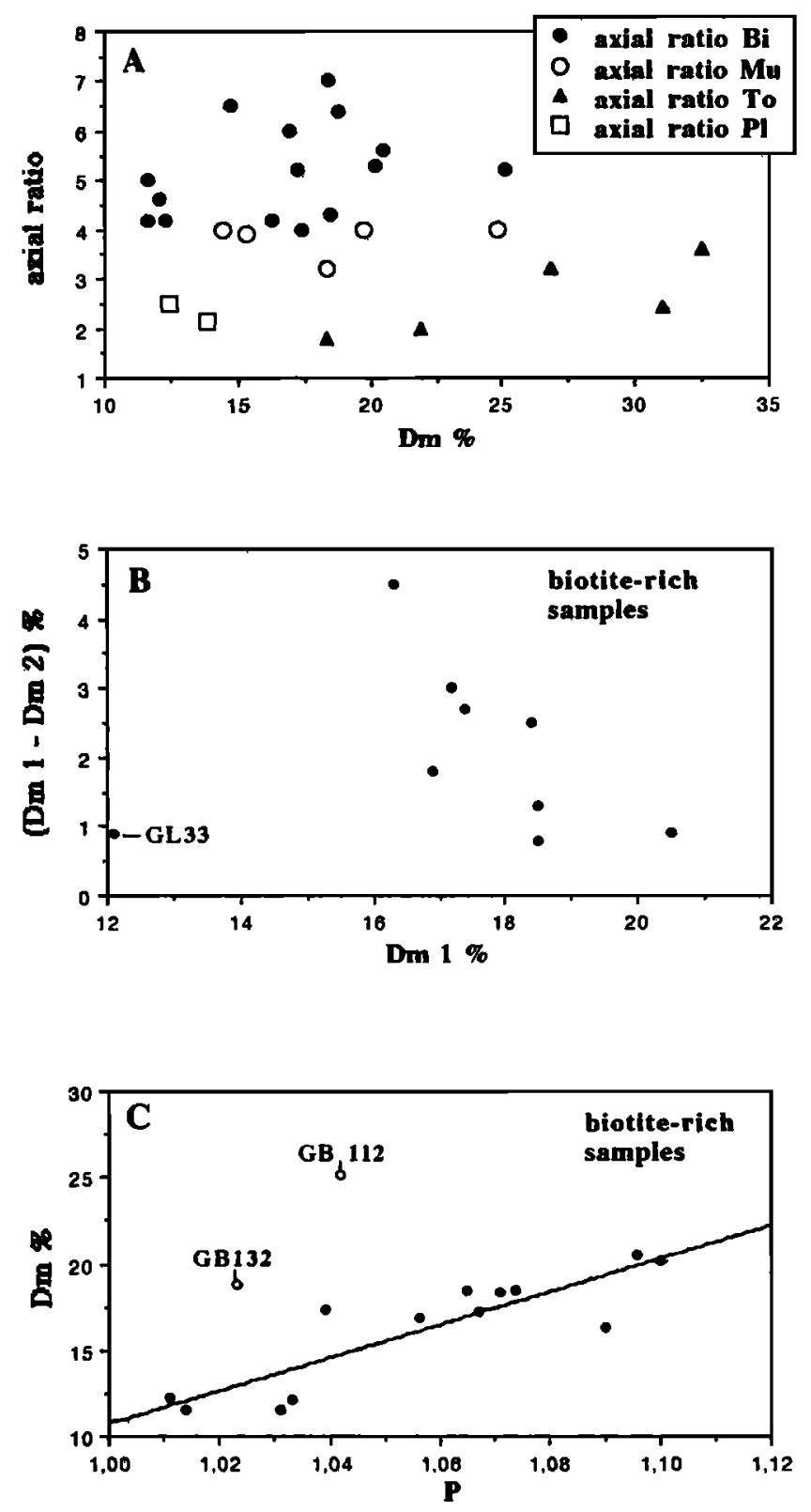

Figure 13. Mineral shape fabric (SPO) of the leucogranites. (a) Axial ratio versus $D_{m} . D_{m}$ is an indicator of the strength of the fabric (see text). (b) Difference in the $D_{m}$ obtained on two perpendicular thin sections for the same sample $\left(D_{m 1}-D_{m 2}\right)$, versus the higher value of $D_{m}$ obtained $\left(D_{m 1}\right)$. (c) $P\left(=K_{1} / K_{3}\right)$ parameter of the magnetic ellipsoid versus the higher value of $D_{m}$ obtained on one sample. See text for explanation.

ended with an increase in pressure that implies an additional burial of around $5 \mathrm{~km}$. To explain this phenomenon, Hodges et al. [1988] suggested the emplacement of a southward propagating thrust. In Central Nepal, a similar late metamorphic pressure increase has been documented from a fluid inclusion study by Boullier et al. [1991], but they relate the overloading to the stacking of the gravity folds during extensional collapse tectonics. In the Gangotri area, this second interpretation is favored (1) because of the northward shifting of the feeder dikes system (Figures $4 c$ and $4 d$ ), and (2) because of the systematic obliquity of the metasedimentary rock foliation at the southern contact of the Kedar valley lenses (Figure 3).
Despite the obvious pinch and swell type geometry, several features are inconsistent with the disruption of an earlier single laccolithic intrusion by boudinage. First, the lack of plastic textures in the granite, as well as the local penetrative magmatic layering of tourmaline, or the pronounced SPO fabric, imply boudinage prior to the completion of granite crystallization. This strongly suggests that the granite magma was less viscous than the surrounding schists, which means that rather than boudins, the mechanism advocated here led to mullions ([e.g., Smith , 1975, 1977]. Except for one case (section 9, Figure 6), the geometry of the lenses is not as symmetric (i.e., only the upper contacts of the granite are deformed and the basal contacts are nearly flat) as would be expected from a pinch and swell instability growing on a layer less competent than its surrounding. Finally, if the overloading was related to the northward collapse of the sedimentary pile, there should be a dominant N-S stretching lineation within the lenses. The presence of such an N-S stretching is very difficult to demonstrate, as (1) the partition between collapse and lateral shearing deformations cannot be easily depicted, and (2) the shear vorticity in the structural level where the granitic lenses are emplaced remains moderate, as indicated by the coupling of granite lenses and the tilted feeder dike system (Figure $4 c$ ).

An alternative hypothesis is to consider each lens as an independent laccolith. Since the pioneering work of Gilbert [1877] in the Henry Mountains, Utah, the laccolith type of emplacement of intrusive bodies has been the subject of extensive field and theoretical work (see review by Corry [1988]). According to Gilbert [1877], laccolithic intrusions are floored bodies largely concordant with their surroundings, fed from below by a dike and displaying a circle shape in plan view. Their terminal geometrical evolution is marked by steep-sided walls and a flat top. In some cases, they can be bound by a peripherical fault, which corresponds to local failure of the overburden after being bent by the injected magma. Their depth of intrusion typically lies between 900 and $2300 \mathrm{~m}$, and their level of emplacement seems to be determined by a strong mechanical discontinuity, such as an abrupt lithological change $[M u d g e, 1968]$. Other characteristic features of natural laccoliths include blunt terminations of associated sill and dikes and the brecciation of the surrounding rocks as well as of the laccolith near the contacts [Johnson and Pollard, 1973].

It is worth pointing out that several characteristics listed above either take a different form or are lacking in the southern lenses. According to current thermabarometric estimates [Guillot et al., 1994], the depth of intrusion is much greater, between 10 and $15 \mathrm{~km}$. At the map scale the laccoliths cannot be considered as concordant intrusions (i.e., they are not located at the interface between the HHC and the Harsil formation). At or close to the contact, the host rocks as well as the granite are not brecciated. This is also true for the associated sills present nearby the main intrusions. Furthermore, it has been suggested [Johnson and Pollard, 1973; Dixon and Simpson, 1987] that owing to high crystal content (up to $50 \%$ in volume), magma-forming laccoliths may have a finite yield strength, a view at variance with the inferred crystal-poor character of the Gangotri lenses at the time of their emplacement [Scaillet et al., 1990]. Nevertheless, these differences do not necessarily imply that the southem lenses did not grow as true laccoliths. Rather, the textural differences might in part reflect the higher pressure of emplacement of the Gangotri leucogranites. In particular, the 

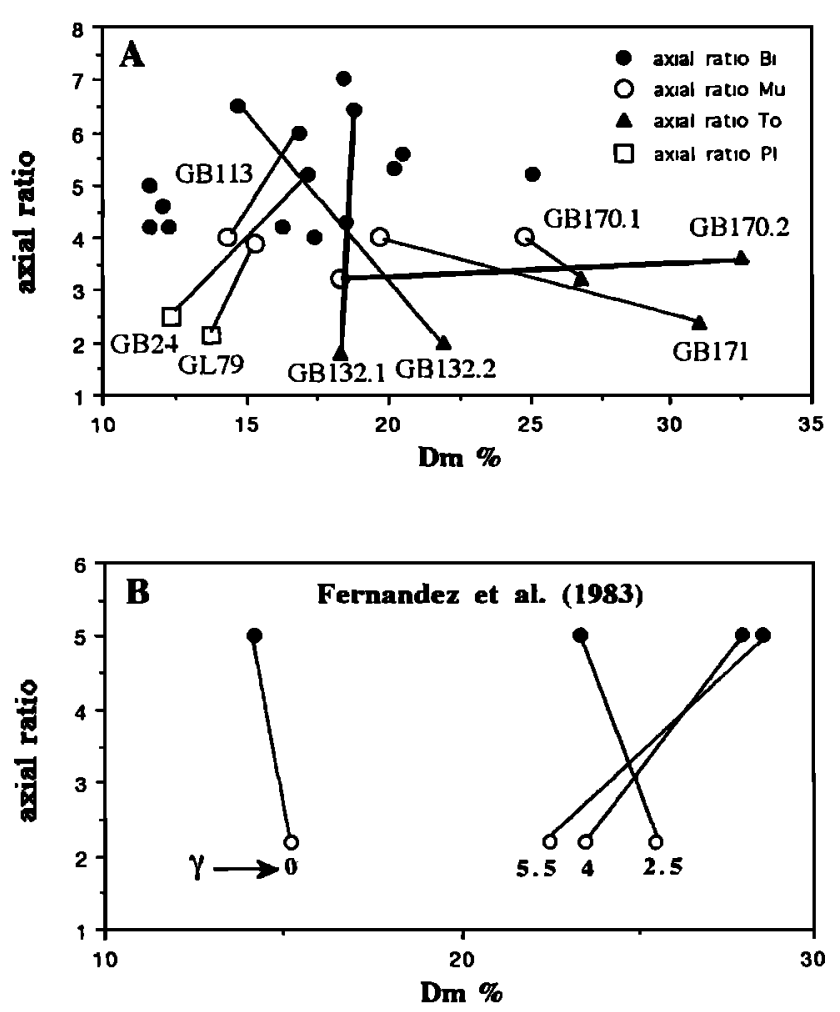

Figure 14. Relation between the average elongation of the minerals (ar, axial ratio) and the intensity of their best orientation $\left(D_{m}\right)$. (a) Data for the Gangotri samples. (b) Values recomputed from experimental results of Fernandez et al. [1983]. The tie lines join pairs of minerals of contrasted shapes in a same thin section (Figure 14a) or in a same experiment (Figure 14b). $\gamma$ is the shear value for the different experimental runs. Experimental data show that in the case of simple shear deformation, less elongated markers cannot reach high values of $D_{m}$. The higher values observed in the Gangotri granites would indicate a significant flattening component.

lack of brecciation and of peripherical faults for the more evolved laccoliths are probably consequences of the deeper level of these intrusions, which allowed a more ductile behavior of the host rocks. It should be noted, however, that the hypothesis of several laccoliths implies that each one has its own system of feeder dikes.

To summarize there are two possibilities: either a large laccolith was subsequently disrupted by the extensional tectonic regime, or there were several laccoliths each with its own feeder dike system. In the next section we use the mathematical model of Pollard and Johnson [1973] on the mechanism of laccolith growth in an attempt to solve this issue.

\section{Laccolithic Development in the Himalaya}

The mechanism of laccolith growth and its effects on the overburden have been given a firm theoretical basis by D. D. Pollard and coworkers [e.g., Johnson and Pollard, 1973; Pollard and Johnson; 1973, Pollard et al., 1975; Pollard and Muller, 1976; Jackson and Pollard, 1988]. In addition, recent centrifuge modeling experiments carried out by Dixon and Simpson [1987] have successfully reproduced the different stages of laccolith growth. In the following, we apply some of the theoretical equations derived by Pollard and Johnson [1973] to the southem lenses, for which accurate values for thickness and radius can be measured. However, it is important to note that these laccoliths are not circular in plan view. Rather, following the terminology of Pollard and Johnson [1973], they have an anticlinal plan shape, or an elliptical plan view with one "infinite" axis, in this case, parallel to the ENE-WSW orientation of the feeder dike zone (Figure 2). The radius of the intrusion, $a$, is perpendicular to this infinite axis. As a rule, the radii of the laccoliths range between 3 and 3.5 $\mathrm{km}$, whereas their thicknesses vary between 1 and $2 \mathrm{~km}$. Thus a model laccolith with a radius of $3 \mathrm{~km}$ and a thickness of $2 \mathrm{~km}$ will be used in order to test the hypothesis of several laccoliths. For the boudinage model, the radius of the hypothetical predisrupted laccolith is $6 \mathrm{~km}$ and its thickness is also $2 \mathrm{~km}$.

According to the elastic bending model developed by Pollard and Johnson [1973], the deflection $w$ of the strata overlying a laccolith having an anticlinal plan shape is given by

$$
w=\left(P d\left(1-u^{2}\right) /\left(2 E T_{E}{ }^{3}\right)\right)\left(a^{2}-x^{2}\right)^{2}
$$

where $P d$ is the magmatic driving pressure and $u, E$, and $T_{E}$ are the Poisson's ratio, the Young's modulus, and the effective thickness of the overburden, respectively. At the center of the intrusion, $x=0$, and the relation (1) becomes

$$
W_{m}=\left(P d\left(1-u^{2}\right) /\left(2 E T_{E}^{3}\right)\right) a^{4}
$$

where $W_{m}$ is the maximum deflection of the overburden (i.e., the maximum thickness of the laccolith). Apart from the radius of the intrusion, which is directly available from the field, all other parameters need to be estimated. The value of the Poisson's ratio was taken as 0.28 [Clemens and Mawer, 1992]. The strata overlying the laccolith are characterized by a succession of regularly alteming schist and sandstone or calcareous beds, each 10 to $20 \mathrm{~cm}$ thick, suggesting that the whole metasedimentary sequence has a low Young's modulus of $10^{10} \mathrm{~Pa}$. The magmatic driving pressure $P d$ is defined as the difference between the lithostatic pressure at the level of emplacement and the magma pressure at the melting zone. The relation is

$$
P d=\left(P s-\mathrm{g}_{m} h\right)-P_{1}
$$

where $P_{s}$ and $P_{l}$ are the lithostatic pressure at the melting zone and at the level of emplacement respectively, $h$ is the height above the source, and $\mathrm{g}_{m}$ is the density of the magma. The large uncertainties associated with the input values in equation (3) prevent an accurate estimation of $P d$. Thus for our specific problem, $P d$ at the feeder was calculated assuming that at the cessation of the intrusion, the magmatic pressure just balanced the downward forces due to the weight of the overburden and to the strength of the magma [Pollard and Johnson, 1973].The general relation is

$$
P d=W_{m}\left(2 k / a+g_{m}\right)
$$

where $k$ is the yield strength of the magma. Field, petrological, and geochemical evidence [Scaillet et al., 1990] as well as available experimental data on silicate melt rheology [Dingwell et al., 1993] point to a Newtonian 
behavior for the Gangotri magma at the time of its emplacement, that is $k=0$. Thus equation (4) can be reduced to the simple expression

$$
P d=W_{m} g_{m}
$$

Using a value of $2300 \mathrm{~kg} / \mathrm{m}^{3}$ for $\mathrm{g}_{m}$ (calculated for a leucogranite composition with 6 wt. $\% \mathrm{H}_{2} \mathrm{O}$ with partial molar volumes of metal oxide components taken from Lange and Carmichael [1990] and a value of $20 \mathrm{~cm}^{3} / \mathrm{mol}$ for $\mathrm{H}_{2} \mathrm{O}$ ) with $W_{m}=2 \mathrm{~km}$ gives a magmatic driving pressure of $46 \mathrm{MPa}$ (note that in both hypotheses, $P d$ has the same value). The last parameter needed to be determined is the effective thickness, that is, the thickness of a single elastic plate having the same resistance to bending as the stack of metasedimentary layers overlying the lenses. This parameter is obviously impossible to determine precisely from the field, as we do not have detailed knowledge of the stratigraphic column present above the lenses at the time of the intrusion. However, Pollard and Johnson [1973] and Jackson and Pollard [1988] have shown that, during the growth of a laccolith, the transition between the sill and the laccolith stage occurs when the radius is roughly twice the effective thickness $T_{E}$ and that this transition radius may be $60 \%$ shorter than the final radius [Jackson and Pollard, 1988]. Assuming that the same relation holds true here, we obtain an effective thickness $T_{E}=1 \mathrm{~km}$ (i.e., $60 \%$ of $3 / 2 \mathrm{~km}$ ) or approximately $10 \%$ of the inferred true thickness (10 to $15 \mathrm{~km}$ for a pressure of emplacement around 4 kbar, [Guillot et al., 1994]). For a single laccolith with $a=6 \mathrm{~km}$, the same reasoning gives $T_{E}=2 \mathrm{~km}(60 \%$ of $6 / 2 \mathrm{~km}$ ).

Using all the above derived $\left(T_{E}, g_{m}, P d, E, u\right)$ or measured (a) parameters, the maximum theoretical deflection $W_{m}$ predicted by equation (2) is $170 \mathrm{~m}$ for the hypothesis of several laccoliths and $343 \mathrm{~m}$ for a single laccolith. These are about one order of magnitude lower than observed deflection $(2 \mathrm{~km})$. This disagreement may be due to wrong values for some of the input parameters. Apart from $a$, in order to increase $W_{m}$ either $P d$ must increase or $E$ and/or $T_{E}$ must decrease. However, increasing $P d$ up to $100 \mathrm{MPa}$ will only increase $W_{m}$ to $373 \mathrm{~m}$ (for the first hypothesis) which is still well below the observed value. On the other hand, the preferred value of $E$ lies at the lower end of the range of values for geological materials and hence cannot be lowered much more. Therefore only $T_{E}$ can still be significantly varied. A vertical deflection of $2 \mathrm{~km}$ is found with an effective thickness $T_{E}=440 \mathrm{~m}$ for several laccoliths and with $T_{E}=1111 \mathrm{~m}$ for a single laccolith.

It is worth noting that both $T_{E}$ values are not very different. Thus, although the large uncertainties associated with the parameters used in this model make it difficult to determine whether there was one or several laccolith(s), the important point is that the laccolithic shape preserved by the Gangotri lenses may be representative of a mechanism of laccolithic growth. The effective thicknesses required in this model, around a few hundred meters, are comparatively much lower than the thicknesses obtained from thermobarometric investigations carried out on the thermal aureoles of the HHL [Guillot et al., 1993a]. This is especially true if the laccoliths are considered to be independent from each other. However, in the Gangotri area, two factors may have contributed to lower the effective thickness. The first is the lithological nature of the overburden, which is characterized by abundant interbedded levels of schist. It is clear that these levels acted as lubricants between the more competent sandstone or calcareous beds, thereby reducing the resistance of the whole sedimentary pile to bending. Let us consider, as an example, that the overburden was composed of a sedimentary pile $10 \mathrm{~km}$ thick, consisting of regularly alterning sandstone and schist layers, each having a thickness $t=20 \mathrm{~cm}$. In this case the effective thickness can be calculated using the following relationship [Pollard and Johnson, 1973]:

$$
T_{E}=\left(h t^{2}\right)^{1 / 3}
$$

and by assuming that the schist levels allowed the sandstone beds to slide freely on each other. In this extreme case it is found that $T_{E}$ is only $7 \mathrm{~m}$. Although this calculation is very rough, it serves to emphasize the highly important role of the lithological nature of the overburden on the mechanism of laccolithic growth. It also shows that given an appropriate lithology, effective thicknesses can be much lower than true thicknesses and that the values found here are probably realistic. The second factor is the extensional regime that may have alleviated the weight of the overburden, if, for instance, collapse folds were activated higher in the sedimentary pile at the time of the intrusion. These two points therefore suggest that a very low effective thickness is not incompatible with a deep laccolithic intrusion. However, it is clear that our understanding of the mechanic of laccolithic intrusion in the High Himalayan range is still hampered by several points which warrant further investigations. First, neither experimental nor theoretical modeling have to date investigated the effects of nonhorizontal strata on laccolith growth. Second, the model developed by Pollard and Johnson [1973] strictly applies to laccolith growth largely unaffected by adjacent intrusions, which may be not the case here. For instance, the discordance noted on the north flank of the southem intrusion on Figure 3 may be ascribed to the consecutive growth of the northern laccolith. Third, laccoliths generally occur in geological environments devoid of tectonic stresses. Although a post-MCT emplacement has been inferred for the Gangotri laccoliths, their geometry was probably affected by the extensional collapse working at the top of HHC. For example, the noted eastward increase in laccolith asymmetry (Figures 5 and 6) may be ascribed to an increasing amount of extension in that direction. Given that the relative importance of each of these parameters is still difficult to estimate, the results obtained here although encouraging, must be considered with caution. Nevertheless, we stress that whatever the number of lenses initially emplaced, they represent the first documented example(s) of deeply intruded laccolith(s) in a continental collision zone.

\section{Rate of Magma Emplacement in the Himalaya}

Radiometric ages obtained by U-Pb [Shärer et al., 1986] and Rb-Sr [Deniel et al., 1987] methods on some HHL suggest that magma emplacement in the Himalayas occurred over impressively long periods, about $7 \mathrm{Ma}$, although recent results of a ${ }^{39} \mathrm{Ar}-{ }^{40} \mathrm{Ar}$ study carried out on the Manaslu granite [Copeland et al., 1990] indicate that the magmatic history could have been shorter (1-4 Ma). Several lines of evidence argue against the Gangotri lens-magma having been slowly intruded. Thermobarometric estimates by Guillot et al. [1994] on the Manaslu granite indicate a maximum temperature of the host rocks at the time of magma intrusion of around $550^{\circ} \mathrm{C}$. 
Field evidence as well as a metamorphic reconnaissance study (B. Scaillet, unpublished data, 1993) point to a similar, or even lower metamorphic grade (especially for the northernmost lenses) at the level of Gangotri lenses. On the other hand, the experimental results of Scaillet et al. [1991] imply melt temperatures between $800^{\circ} \mathrm{C}$ and $700^{\circ} \mathrm{C}$. Finally, the detailed study of Deniel et al. [1987] shows that the length of individual magma batches is $100 \mathrm{~m}$ or even less. Overall, these facts indicate that the lenses were built by the accretion of small magma batches with a limited heat budget and which once emplaced in a rather cold environment, must have crystallized very rapidly, in less than 500 years according to the calculations of Davidson et al. [1992]. Thus an emplacement lasting several million years should yield features such as (1) clear evidence of earlier intrusions injected by later ones, (2) extensive ballooning processes, (3) abundant aplite and pegmatitic dikes present inside the granite, and also (4) much less perfectly shaped lenses, with less regular limits. Evidence for the first point has been found in only one outcrop [Scaillet et al., 1990]. The very limited occurrence of ballooning effects has already been pointed out. The third point is the direct consequence of a fractional crystallization process, which is known to be efficient in these leucogranites [Scaillet et al., 1990]. As with every granite, each single magma batch should end up with its own system of aplitic and pegmatitic dikes as by-products of crystal fractionation processes. In the Gangotri lenses, these dikes are almost exclusively located either between the leucogranite and its country rocks (northern lenses) or within the host rocks (southern lenses) [Scaillet et al., 1990]. This implies that once the melt batches were emplaced, all the residual liquids or volatiles exsolved as the crystallization proceeded were able to migrate upward and were not trapped between the different melt pods. Such a process seems more likely to have occurred if the entire granite was once almost entirely liquid. This in turn implies short times of magma injection. Similarly, perfectly shaped laccoliths require that the magma behaved as a homogeneous rheological medium during the growth stage. This would not have been possible if the magma had large coexisting domains that behaved as solid, partly liquid, and liquid, as implied by an emplacement that occurred over several million years. Furthermore, in the latter, successive accretion of magma batches would have lead to much more lobate contacts which is not the case of the Gangotri granite where straight contacts are observed along several hundred meters (Figure 3). Last, the vertical attitude of the feeder system also argues against the intrusion of magma over several million years. As pointed out previously, this indicates a maximum principal compressive stress that was nearly vertical during the period of magma injection. It is highly unlikely that such a stress regime persisted continuously for millions of years.

The above evidence suggests that the melt supply through the dike system was a continuous rather than a pulsed or intermittent phenomenon. Calculations performed by Clemens and Mawer [1992] and Petford et al. [1993] show that contrary to a widely held belief, the rise of granitic melts through dikes and their emplacement at higher crustal levels are extremely fast processes (see also Paterson and Tobish [1992]). For instance, it takes only 900 years to inflate a batholith of $2000 \mathrm{~km}^{3}$ by a single dike $4 \mathrm{~m}$ thick $1 \mathrm{~km}$ length and $23 \mathrm{~km}$ long. Considering the fact that the volume of the southern lens below which the feeder system is seen is about
$150 \mathrm{~km}^{3}$ and that the feeder system is made up of hundreds of dikes each 10 to $20 \mathrm{~m}$ thick (Figures $4 \mathrm{c}$ and $4 \mathrm{~d}$ ) these calculations suggest a building period shorter than 100 years. Such a short time of magma emplacement is in fact a characteristic of many laccolithic intrusions [Corry, 1988] as shown by the centrifuge modeling of Dixon and Simpson [1987], which indicates that laccolith formation can be achieved in periods as short as one year to a few decades.

Therefore field evidence combined with the current knowledge on the rate of magma transport trough fractures [Clemens and Mawer, 1992; Petford et al. , 1993] and on the rate of laccolith formation [Corry, 1988; Dixon and Simpson, 1987] suggest that the Gangotri laccoliths were emplaced in impressively brief times, 4 orders of magnitude shorter than that estimated for other HHL [e.g., Deniel et al., 1987; Copeland et al., 1990].

\section{Conclusions}

This study shows that the Gangotri laccoliths are not simply related to the MCT southward thrusting. Their tectonic pattern implies an emplacement in an overall extensional regime. Thus, despite the fact that the melt generation is closely related to the continental collision process, the structures of the granite only record the extensional regime that was paired with crustal thickening processes [see Dewey, 1988]. The occurrence of a laccolith is dependent on at least two important factors. First, the overburden needs to have an appropriate lithology in order to reduce the effective thickness or its resistance to bending. Second, flat-lying collapse structures, which may be either folds or freely sliding planes, need to be contemporaneous with fracture propagation. It is therefore obvious that a schist-rich metasedimentary sequence will favor the development of laccolith as it has a lower resistance to bending than other geological materials and it may favor or accentuate collapse tectonics if an appropiate extensional stress field prevails. The lack of one of these two factors may limit or even suppress the possibility for laccolithic growth to occur.

The Gangotri granites are a part of a larger set of HHL granites widespread all along the $2000 \mathrm{~km}$ of the Himalayan orogenic belt. The lensoid (i.e., laccolithic) shape of many of the HHL granites has long been recognized by several authors [e.g., Gansser, 1964; Le Fort, 1975; 1981; Burg et al., 1984; Castelli and Lombardo, 1988], and recent studies have emphasized the importance of extensional tectonics at the top of the HHC, in the zone where these granites were emplaced [Caby et al., 1983; Burg et al., 1984; Burchfiel and Royden, 1985; Herren, 1987; Mattauer and Brunel, 1989; Pêcher and Scaillet, 1989; McElroy et al., 1990; Boullier et al., 1991]. Among areas (i.e., between Nepal, Zanskar or Garhwal Himalaya), granite emplacement either preceded or coincided with extension. This variation in the timing of granite emplacement probably does not imply very different mechanisms in melt collection and emplacement but rather is due to the difficulty in clearly distinguishing between successive sets of extensional structures (normal faulting from collapse structures). This apparent temporal variation complicates direct comparisons between the different Himalayan leucogranites. However, some differences or similarities can be noted. Most of the other plutons, such as the Manaslu (thickness around $6 \mathrm{~km}$ [Guillot et al., 1993a]), or the Everest-Makalu in central Nepal are comparatively 
much larger and thicker than the Gangotri lenses. However, those plutons that grade westward in the large Badrinath body [Heim and Gansser, 1939; Blattner et al., 1983] define a regional pattern very similar to the pattern observed in Bhutan [Gansser, 1983], with huge leucogranites plutons surrounded by much smaller lenticular bodies. This disposition suggests that the Gangotri laccoliths may be representative of the initial stage of pluton accretion which ultimately gave rise to a much bigger massif such as the Manaslu granite. Altematively, this can be interpreted as having resulted from a crustal scale boudinage mechanism. In this respect, the Nuptse fold of the Everest-Makalu granite may be viewed as a large-scale boudin formed during intrusion, whereas it was previously interpreted by Bortolami et al. [1983] as resulting from tertiary folds affecting the granite after its emplacement.

The HHC is characterized by dextral shearing which is responsible for the E-W stretching lineation in the HHL [Pêcher and Scaillet, 1989; Pêcher, 1991]. This shearing could be an important factor controlling granite structure, as suggested by Guillot et al. [1993] for the Manaslu granite. Although poorly developed in the Gangotri area, this E-W fabric seems to be better defined in the easternmost leucogranites [Guillot et al., 1993], which corroborates the proposal of Pêcher [1991] that the amount of shear associated with this dextral wrench should increase eastward. However, as already stated, it should not be concluded that this dextral shear zone is the dominant factor in the magma emplacement for the northernmost intrusions, as proposed for the Manaslu granite by Guillot et al. [1993]. Although not measured in the area of interest, slip rates of shear zones do not greatly exceed 3-7 $\mathrm{cm} \mathrm{y}^{-1}$ [Paterson and Tobisch, 1992]. This implies that it would take approximately $10^{5}$ years to open a hypothetical $10-\mathrm{km}$-long cavity, corresponding to the E-W length of the northern intrusion. Therefore, given the very short periods of magma emplacement inferred in this study $\left(<10^{2}\right.$ years), the displacements along this shear zone would have been too slow to create the volume necessary to accommodate the incoming magma. Consequently, although their structural pattern in plan view bears some similarities to other granitic intrusions emplaced along pull apart or extensional shear zones [Guinberteau et al., 1987; Hutton et al., 1990; Bouillin et al., 1993], it is probable that the northern lenses mainly recorded the late activity of this shear zone. This implies that the current mesofabric of the granite is not representative of its mechanism of emplacement. It is worth pointing out that the laccolithic mode of growth implies that the magma by itself is able to push aside its country rocks [see Paterson and Fowler, $1993 \mathrm{a}, \mathrm{b}]$. In other words, there is no room space problem for a laccolithic intrusion and hence no need to call upon an hypothetical tectonic aperture of the future magma chamber [e.g., Hutton et al., 1990; Bouillin et al., 1993].

More globally, the Garhwal lenses show in a most spectacular way that a granite rise throughout the crust is not restricted to diapiric ascent. They are unique examples of granites in that field data dictate not only their overall 3-D geometry but also, and this is rarely found, their mechanism of ascent and intrusion. In this respect, the insight gained from this study can help decipher the structure of similar leucogranites in other mountain ranges (e.g., the Hercynian belt), in which the three-dimensional shapes of the massifs are poorly constrained. This is important because the extensional tectonic regime is increasingly being recognized as a critical factor in the evolution of older orogens [e.g., Mattauer et al., 1988; Faure and Pons, 1991] as well as in the kinematics of granitoids emplacement [e.g., Hutton et al., 1990; Bouillin et al.,1993].

Acknowledgments. Field and laboratory works were supported by grants from the Commissariat à l'Energie Atomique (C.E.A.) and by the GRECO Himalaya-Karakorum of CNRS. We are grateful for stimulating discussions with $P$. Le Fort, J. Dardel and $M$. Searle in the field and with J.L. Bouchez in the laboratory. The thorough review of J.P. Hogan is gratefully aknowledged. R. Linnen helped to improve the English of the manuscript.

\section{References}

Arzi, A.A., Critical phenomena in the rheology of partially melted rocks, Tectonophysics, 44, 173-184, 1978.

Auden, J.B., Tehri Garhwal and British Garhwal, Rec. Geol. Surv. India, 76, 74-78, 1949.

Bateman, R., Progressive crystallization of a granitoid diapir and its relationship to stages of emplacement, J. Geol., 93, 645-662, 1985.

Benn, K., and B. Allard, Preferred mineral orientations related to magmatic flow in ophiolite layered gabbros, J. Petrol., 30, 925 946, 1989.

Bernier, S., J.L. Bouchez, and P. Rochette, Anisotropie de la sucsepibilite magnetique du granite de beauvoir, C. R. Acad. Sci., 305, 1167-1173, 1987.

Blattner, P., V. Dietrich, and A. Gansser, Contrasting $O^{18}$ enrichement and origins of High Himalayan and Transhimalayan intrusives, Earth Planet. Sci. Lett., 65, 276-286, 1983.

Blumenfeld, P., and J.L. Bouchez, Shear criteria in granite and migmatite deformed in the magmatic and solid states, J. Struct. Geol., 10, 361-372, 1988.

Bortolami, G., B. Lombardo, and R. Polino, The granites of the upper Imja Khola (Everest region), eastern Nepal, Graniles of Himalayas, Karakorum and Indu Kush, pp. 257-270, edited by F.A. Shams, Institute of Geology, Punjab University, Lahore, Pakistan, 1983.

Bouchez, J.L., S. Bernier, P. Rochette, and B. Guineberteau, Log des susceptibilités magnétiques et anisotropies de susceptibilités dans le granite de Beauvoir: Conséquences pour sa mise en place, Geol. Fr, 2-3, 223-232, 1987.

Bouchez, J.L. G. Gleizes, T. Djouadi, and P. Rochette, Microstructure and magnetic susceptibility applied to emplacement kinematics of granite: The example of the Foix pluton (French Pyrénees), Tectonophysics, 184, 157-171, 1990.

Bouillin, J.P., J.L. Bouchez, P. Lespinasse, and A. Pêcher, Granite emplacement in an extensional setting: an AMS study of the magmaic structures of Monte Capanne (Elba, Italy), Earth Planet. Sci. Lett., 118, 263-279, 1993.

Boullier, A.M., C., France-Lanord, J., Dubessy, J., Adamy, and M. Champenois, Linked fluid and tectonic evolution in the High Himalaya mountains (Nepal), Contrib. Mineral. Petrol., 107, 358372, 1991.

Brun, J.P., and J. Pons, Strain pattems of pluton emplacement in a crust undergoing non coaxial deformation, Sierra Morena, Southem Spain, J. Struct. Geol., 3, 219-229, 1981.

Burchfiel, B.C., and L.H. Royden, North-South extension within the convergent Himalayan region, Geology, 12, 679-682, 1985.

Burchfiel, B.C., and L.H. Royden, Thin skinned N-S extension within the convergent Himalayan region: Gravitational collapse of a Miocene topographic front. Continental Extensional Tectonics, edited by M.P. Coward, J.F. Dewey, and P.L. Hancock, Pp. 611619, Geol. Soc. Spec. Publ., London, $28,1987$.

Burg. J.P., M. Brunel , D. Gapais , G.M. Chen, and G.H. Liu, Deformation of the leucogranites of the crystalline main central sheet in southern Tibet (China), J. Struct. Geol., 6, 532-542, 1984. 
Caby, R, A. Pêcher, and P. Le Fort, Le grand chevauchement central himalayen: nouvelles données sur le métamorphisme inverse à la base de la Dalle du Tibet, Rev. Géol. Dyn. Géogr. Phys., 24, 89$100,1983$.

Castelli, D., and B. Lombardo, The Gophu La and Westem Lunana granites: Miocene muscovite leucogranites of the Bhutan Himalaya, Lithos, 21, 211-225, 1988.

Castro, A., Structural pattem and ascent model in the Central Extremadura batholith, Hercynian belt, Spain, J. Struct. Geol., 8, $633-645,1986$.

Clemens, J.D., and C.K. Mawer, Granitic magma transport by fracture propagation. Tectonophysics, 204, 339-360, 1992.

Copeland, P., T.M. Harrison, and P. Le Fort, Age and cooling history of the Manaslu granite: implications for Himalayan tectonics, $J$. Volcano. Geotherm. Res., 44, 33-50, 1990.

Corry, C.E., Laccoliths: Mechanisms of emplacement and growth, Spec. Pap. Geol. Soc. Am., 220, 110 pp, 1988.

Davidson, C., L.S. Hollister, and S.M. Schmid, Role of melt in the formation of a deep-crustal compressive shear zone: The Maclaren Glacier metamorphic belt, south central Alaska, Tectonics, 11, 348-359, 1992.

Deniel, C., P. Vidal, A. Femandez, and P. Le Fort, Isotopic study of the Manaslu granite (Himalaya, Nepal): Inferences on the age and source of Himalayan leucogranites, Contrib. Mineral. Petrol., 96, 78-82, 1987.

Dewey, J.F., Extensional collapse of orogens, Tectonics, 7, 1123$1139,1988$.

Dingwell, D.B., N.S. Bagdassarov, N.S. Bussod, and S.L. Webb, Magma Rheology, Experiments at high pressure and applications to the earth's mantle, Short Course Hand. 21, edited by R.W. Luth, pp. 131-196, Mineralogical Association of Canada, Nepean, Ont., 1993.

Dixon J.M., and D.G. Simpson, Centrifuge modeling of laccolith intrusion, J. Struct. Geol., 9, 87-103, 1987.

England, P., P. Le Fort, P. Molnar., and A. Pêcher, Heat sources for tertiary metamorphism and anatexis in the Annapurna-Manaslu region, central Nepal, J. Geophys. Res., 97, 2107-2128, 1992.

Faure, M., and J. Pons, Crustal thinning recorded by the shape of the Namurian-Westphalian leucogranite in the Variscan belt of the northwest Massif Central, France, Geology, 19, 730-733, 1991.

Fernandez, A., Preferred orientation developed by a rigid markers in two dimensional simple shear strain: A theoretical and experimental study, Teclonophysics, 136, 151-158, 1987.

Femandez, A., and D. Laporte, Significance of low symmetry fabrics in magmatics rocks, J. Struct. Geol., 13, 337-347, 1991.

Fernandez, A., J.L. Feybesse, and J.L. Meyzure, Theoretical and experimental study of fabrics developed by different shaped markers in two-dimensional simple shear, Bull. Soc. Géol. Fr., 7, 319-326, 1983.

France-Lanord, C., and P. Le Fort, Crustal melting and granite genesis, Trans. R. Soc. Edinburgh Earth Sci., 79, 183-195, 1988.

Gansser, A., Geology of the Himalayas, 289 pp., John Wiley, New York, 1964.

Gansser, A., Geology of the Bhutan Himalaya., Mém. Soc. Helv. Nat, 96, 181 pp., Birkhaüser, Basel Switzerland, 1983.

Gilbert, G.K., Report on the geology of the Henry Mountains, Rocky Mountains Region, 160 pp., U.S. Geol. Surv., Reston, Va., 1877.

Gleizes, G., A. Nedelec, J.L. Bouchez, A. Albert, and P. Rochette, Magnetic susceptibility of the Mont-Louis Andorra ilmenite type granite (Pyrénées): A new tool for the petrographic characterization and regional mapping of zoned granite plutons, $J$. Geophys. Res., 98, 4317-4331, 1993.

Guillet, P., J.L. Bouchez, and G. Wagner, Anisotropy of magnetic susceptibility and magmatic structures in the Guérande granite massif-France, Tectonics, 2, 419-429, 1983.

Guillot, S., A. Pêcher, P. Rochette, and P. Le Fort, The emplacement of the Manaslu granite of Central Nepal. Field and magnetic susceptibility constraint, Himalayan Tectonics, edited by P.J., Treloar, and M.P., Searle M.P., Geol. Soc. Spec. Publ. London, 74, 413-428, 1993.
Guillot, S., P. Le Fort, A. Pêcher, M. Roy Barman, and J. Aprahamian, On the depth of emplacement of the Himalayan leucogranites: Estimations about the Manaslu granite, Central Nepal, Tectonophysics, in press, 1994.

Guineberteau, B., J.L. Bouchez, and J.L. Vigneresse, The Mortagne granite pluton (France) emplaced by pull-apart along a shear zone: Structural and gravimetric arguments and regional implication. Geol. Soc. Am. Bull., 99, 763-770, 1987.

Heim, A. and A. Gansser, Central Himalaya, geological observations of the swiss expedition 1936, Mém. Soc. Helv. Sci. Nat., 73, 245 pp., 1939.

Herren, E., Zanskar shear zone: Norheast-southwest extension within the Higher Himalayas (Ladakh, India), Geology, 15, 409413, 1987.

Hodges, K.V., M. Hubbard, and D.S. Silverberg, Metamorphic constraints on thermal evolution of the central Himalayan Orogen, Tectonic Evolution of the Himalayas and Tibet, Philos. Trans. R. Soc. London., 236, 257-280, 1988.

Hodges, K.V., and D.S. Silverberg, Thermal evolution of the greater Himalaya, Garhwal, India, Tectonics, 7, 583-600, 1988.

Hutton, D.H.W., Granite emplacement mechanisms and tectonic controls: inferences from deformation studies, Trans. $R$. Soc. Edinburgh Earth Sci., 79, 245-255, 1988.

Hutton, D.H.W., T.J. Dempster, P.E. Brown, and S.D. Becker, A new mechanism of granite emplacement: Intrusion in active extensional shear zone, Nature, 343, 452-455, 1990.

Ildefonse, B., J.M. Lardeaux, and J.M. Caron, The behavior of shape preferred orientations in metamorphic rocks: amphiboles and jadeites from the Monte Mucrone area (Sesia-Lanzo zone, Italian westem Alps), J. Struct. Geol., 12, 1005-1011, 1990.

Ildefonse, B., P. Launeau, J.L. Bouchez, and A. Femandez, Effetc of mechanical interactions on the development of shape preferred orientations: A two-dimensional experimental approach, J. Struct Geol., 13, 73-83, 1992.

Jackson, M.D., and D.D. Pollard, The laccolith-stock controversy: new results from the southem henry Mountains, Utah, Geol. Soc. Am. Bull., 100, 117-139, 1988.

Jain, A.K., and A. Anand, Deformational and strain patterns of an intracontinental collision ductile shear zone: An example from the Higher Garhwal Himalaya, J. Struct. Geol., 10, 717-734, 1988.

Jaupart, C.L., and A. Provost, Heat focussing, granite genesis and inverted metamorphic gradients in continental collisional zones, Earth Planet. Sci. Lett., 73, 385-397, 1985.

Jelinek, V., Characterization of magnetic fabric of rocks, Tectonophysics, 79, 63-67, 1979.

Johnson, A.M., and D.D. Pollard, Mechanics of growth of some laccolithic intrusions in the Henry Mountains, Utah, I, Field observations, Gilbert's model, physical properties and flow of the magma, Tectonophysics, 18, 261-309, 1973.

Lange, R.A., and I.S.E. Carmichael, Densities of $\mathrm{Na}_{2} \mathrm{O}-\mathrm{K}_{2} \mathrm{O}-\mathrm{CaO}$ $\mathrm{MgO}-\mathrm{FeO}-\mathrm{Fe}_{2} \mathrm{O}_{3}-\mathrm{Al}_{2} \mathrm{O}_{3}-\mathrm{TiO}_{2}-\mathrm{SiO}_{2}$ liquids: New measurements and derived partial molar properties, Geochim. Cosmochim. Acta, 51, 2931-2946, 1987.

Lange, R.A., and I.S.E. Carmichael, Thermodynamic properties of silicate liquids with emphasis on density, themal expansion and compressibility, Modern Methods of Igneous Petrology: Understanding Magmatic Processes, Rev. Mineral., vol. 24, edited by J. Nicholls, and J.K. Russel, J.K., pp. 25-64, Mineralogical Society of America, Washington, D.C., 1990.

Lapique, F., M. Champenois, and A. Cheilletz, Un analyseur vidéographique interactif: description et applications, $B$ ull. Minéral., 111, 679-687, 1988.

Le Fort, P., Himalaya: The collided range. Present knowledge of the continental arc, Am. J. Sci., 275A, 1-44, 1975.

Le Fort, P., Manaslu leucogranite: A collision signature of the Himalaya. A model for its genesis and emplacement, J. Geophys. Res., 86, 10,545-10,568, 1981.

Le Fort, P., Metamorphism and magmatism during the Himalayan collision, Collision Tectonics, edited by M.P. Coward, and A.C. Ries, pp. 159-172, Geol. Soc. Spec. Publ., London, 19, 1986. 
Le Fort, P., The Himalayan orogenic segment, Tectonic Evolution of the Tethyan Region, edited by A.M.C. Sengör, pp. 289-386, Kluwer, Norwell, Mass., 1989.

Le Fort, P., M. Cuney, C. Deniel, C. France-Lanord, S.M.F. Sheppard, B.N. Upreti, and P. Vidal, Crustal generation of the Himalayan leucogranites, Teclonophysics, 134, 39-57, 1987.

Lister, J.R., and R.C. Kerr, Fluid-mechanical models of crak propagation and their application to magma transport in dikes, $J$. Geophys. Res., 96, 10,049-10,077, 1991.

Mattauer, M., and M. Brunel, La faille Nord-Himalayenne (FNNH) conséquence probable d'un diapirisme granitique, C.R. Acad. Sci. 308, 1285-1289, 1989.

Mattauer, M., M. Brunel, and P. Matue, Failles normales ductiles et grands chevauchements: Une nouvelle analogie enire l'Himalaya et la chaîne hercynienne du Massif Central français, C. R. Acad. Sci., 306, 671-676, 1988.

McElroy, R., J. Cater, I. Roberts, A. Peckam, and M. Bond, The structure and stratigraphy of the SE Zanskar, Ladakh Himalaya, $J$. Geol. Soc. London, 147, 989-997, 1990.

Miller, C.F., E.B. Watson, and T.M. Harrison, Perspectives on source, segregation and transport of granitoid magma. Trans. $R$. Soc. Edinburgh Earth Sci., 79, 135-156, 1988.

Molen, I., van der, and M.S. Paterson, Experimental deformation of partially-melted granite, Contrib. Mineral. Petrol., 72, 57-72, 1979.

Molnar, P., Structure and tectonics of the Himalaya: Constraints and implications of geophysical data, Annu. Rev. Earth Planet Sci., 12, 489-518, 1984.

Molnar, P., and P. England, Temperatures, heat flux, and frictional stress near major thrust faults, J. Geophys. Res., 95, 4833-4856, 1990.

Mudge, M.R., Depth control of some concordant intrusions, Geol. Soc. Am. Bull., 79, 315-332. 1968.

Nicolas, A., Kinematics in magmatic rocks with special reference to gabbros, J. Petrol., 33, 891-915, 1992.

Pant, R., Petrochemistry and petrogenesis of the Gangotri granite and associated granitoïds. Garhwal Himalaya, Ph.D. thesis, 120 pp. Univ. of Roorkee, Roorkee, India, 1986.

Paterson, S.R., and T.K. Fowler, Extensional pluton-emplacement models: Do they work for large plutonic complexes?, Geology, 21, 781-784, 1993a.

Paterson, S.R., and T.K. Fowler, Re-examining pluton emplacement processes, J. Struct. Geol., 15, 191-206, 1993b.

Paterson, S.R., and O.T. Tobisch, Rates of processes in magmatic arcs: Implications for the timing and nature of pluton emplacement and wall rock deformation, J. Struct. Geol, 14, 291 $300,1992$.

Paterson, S.R., R.H Vernon, and O.T. Tobisch, A review of the criteria for the identification of magmatic foliations in granitoids, J. Struct. Geol., 11, 349-363, 1989.

Pêcher, A., The contact between the higher Himalaya crystallines and the Tibetan sedimentaries series: Miocene large-scale dextral shearing, Tectonics, 10, 587-598, 1991.

Pêcher, A., and B., Scaillet, La structure du Haut Himalaya au Garhwal (Indes), Eclogae Geol. Helv., 82, 655-668, 1989.

Pêcher, A., J.L. Bouchez, and P. Le Fort, Miocene dextral shearing between Himalaya and Tibet, Geology, 19, 683-685, 1991.

Petford N., R.C., Kerr, and J.R. Lister, Dike transport of granitoid magmas, Geology.21, 845-848, 1993.

Pinet, C., and C. Jaupart, A thermal model for the distribution in space and time of Himalayan granites. Earth Planet. Sci. Lett., 84, 87-99, 1987.

Pollard, D.D., and A.M. Johnson, Mechanics of growth of some laccolithic intrusions in the Henry Mountains, Utah, II, Bending and failure of overburden layers and sill formation, Tectonophysiscs, 18, 311-354, 1973.
Pollard, D.D., and O.H. Muller, the effect of gradients in regional stress and magma pressure on the form of sheet intrusions in cross section, J. Geophys. Res., 81, 975-984, 1976.

Pollard, D.D., O.H. Muller, and D.D., Dockstader, the form and growth of fingered sheet intrusions, Geol. Soc. Am. Bull., 86, 351-363, 1975.

Rochette, P., Magnetic susceptibility of the rock matrix related to magnetic fabric studies, J. Struct, Geol., 9, 1015-1020, 1987.

Rochette, P., B. Scaillet, S. Guillot, A. Pêcher, and P. Le Fort, Magnetic mineralogy of the High Himalayan Leucogranites: Structural implications, Earth Planet. Sci. Lett., in press, 1994.

Scaillet, B., A, Pêcher, P. Rochettte and P. Le Fort, The Gangotri plutons (High Himalaya leucogranite, westem India): An example of a crustal scale "tablette de chocolat" structure, Terra Cognita, 1 , $174,1989$.

Scaillet, B, C. France-Lanord, and P. Le Fort, Badrinath-Gangotri plutons (Garhwal, India): petrological and geochemical evidence for fractionation processes in a high Himalayan leucogranite, $I$. Volcano. Geotherm. Res., 44, 163-188, 1990.

Scaillet, B., M. Pichavant, and J. Roux, Tourmaline, biotite and muscovite stability in felsic peraluminous liquids, Eos, Trans. $A G U, 72$ (17), Spring Meeting Suppl., 311, 1991.

Searle, M.P., R.P. Metcalfe, A.J. Rex and M.J. Norry. Field relations, petrogenesis and emplacement of the Bhagirathi leucogranite, Garhwal Himalaya, Himalayan Tectonics, edited by P.J., Treloar, and M.P., Searle M.P., pp. 429-444, Geol. Soc. Spec. Publ. London, 74, 1993.

Shärer, U., C.J. Allègre and R.H., Xu, U-Th-Pb systematics and ages of Himalayan leucogranites, South Tibet, Earth Planet. Sci. Lett., $77,35-48,1986$.

Smith, R.B., Unified theory of the onset folding, boudinage, and mullion structure, Geol. Soc. Am. Bull., 86, 1601-1609, 1975.

Smith, R.B., Formation of folds, boudinage, and mullions in nonNewtonian materials, Geol. Soc. Am. Bull., 88, 312-320, 1977

Steitz, J.F., A.P. Tewari, and J. Obradovich, A note on the absolute age of the tourmaline granite, Arwa valley, Garhwal Himalaya, Geol. Surv. India, 24, 332-337, 1976.

Stem, C.R., R. Kligfield, D. Schelling, N.S. Virdi, K. Futa, Z.E. Peterman, and H. Amini, The Bhagirathi leucogranite of the High Himalayas (Garhwal, India): Age, petrogenesis, and tectonic implications, Spec. Pap. Geol. Soc. Am. 232, 33-45, 1989.

Valdiya, K.S., An outline of the structural set-up of the Kumaun Himalaya, J. Geol. Soc. India, 20, 145-157, 1979.

Vidal, P., A. Cocherie, and P. Le Fort, Geochemical investigations of the origin of the Manaslu leucogranite (Himalaya, Nepal), Geochim. Cosmochim. Acta, 46, 2279-2292, 1982.

Weertman, J., The stopping of a rising, liquid filled crack in the Earth's crust by a freely slipping horizontal joint, $J$. Geophys. Res., 85, 967-976, 1980.

Wickam, S.M., The segregation and emplacement of granitic magmas. J. Geol. Soc., 144, 281-297, 1987.

Willis, D.G., A kinematic model of preferred orientation, Geol. Soc. Am. Bull., 88, 883-894, 1977.

M. Champenois, CRPG-CNRS, 15 nue Notre Dame des Pauvres, 54501 Vandoeuvre-Lès-Nancy, France.

A. Pêcher, URA 69, CNRS, 15 rue Maurice Gignoux, 38031 Grenoble, France.

P. Rochette, Géochimie et Magnétisme des roches, Faculté Saint Jérôme, 13397, Marseille, France.

B. Scaillet, CRSCM-CNRS, 1A rue de la Férollerie, 45041, Orléans, France.

(Received May 18, 1993; revised June 15, 1994; accepted June 22, 1994, 